\title{
Antinociception of petroleum ether fraction derived from crude methanol extract of Melastoma malabathricum leaves and its possible mechanisms of action in animal models
}

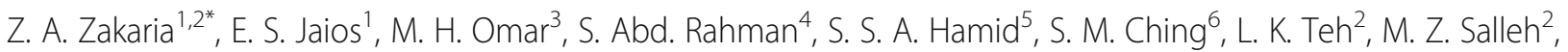

S. Deny ${ }^{7}$ and M. Taher $^{8}$

\begin{abstract}
Background: Melastoma malabathricum L. (family Melastomaceae) has been traditionally used as remedies against various ailments including those related to pain. The methanol extract of $M$. malabathricum leaves has been proven to show antinociceptive activity. Thus, the present study aimed to determine the most effective fraction among the petroleum ether- (PEMM), ethyl acetate- (EAMM) and aqueous- (AQMM) fractions obtained through successive fractionation of crude, dried methanol extract of $M$. malabathricum (MEMM) and to elucidate the possible mechanisms of antinociception involved.

Methods: The effectiveness of fractions (100, 250 and 500 mg/kg; orally) were determine using the acetic acid-induced abdominal constriction test and the most effective extract was further subjected to the hot plate- or formalin-induced paw licking-test to establish its antinociceptive profile. Further elucidation of the role of opioid and vanilloid receptors, glutamatergic system, and nitric oxide/cyclic guanosine phosphate (NO/cGMP) pathway was also performed using the appropriate nociceptive models while the phytoconstituents analyses were performed using the phytochemical screening test and, HPLC-ESI and GCMS analyses.

(Continued on next page)
\end{abstract}

\footnotetext{
*Correspondence: dr_zaz@yahoo.com; zaz@upm.edu.my

'Department of Biomedical Sciences, Faculty of Medicine and Health Sciences, Universiti Putra Malaysia (UPM), 43400 Serdang, Selangor D.E,

Malaysia

${ }^{2}$ Integrative Pharmacogenomics Institute (iPROMISE), Universiti Teknologi MARA (UiTM), Level 7, FF3 Building, 42300 Puncak Alam, Selangor D.E,

Malaysia

Full list of author information is available at the end of the article
} 
(Continued from previous page)

Results: PEMM, EAMM and AQMM significantly $(p<0.05)$ attenuated acetic acid-induced nociception with the recorded $\mathrm{EC}_{50}$ of $119.5,125.9$ and $352.6 \mathrm{mg} / \mathrm{kg}$. Based on the $\mathrm{EC}_{50}$ value, PEMM was further studied and also exerted significant $(p<0.05)$ antinociception against the hot plate- and formalin-induced paw licking-test. With regards to the mechanisms of antinociception,: i) PEMM significantly $(p<0.05)$ attenuated the nociceptive action in capsaicinand glutamate-induced paw licking test.; ii) naloxone ( $5 \mathrm{mg} / \mathrm{kg})$, a non-selective opioid antagonist, failed to significantly $(p<0.05)$ inhibit PEMM's antinociception iii) L-arginine (a nitric oxide precursor), but not $N^{G}$-nitro-Larginine methyl esters (L-NAME; an inhibitor of NO synthase), methylene blue (MB; an inhibitor of CGMP), or their respective combination, significantly $(p<0.05)$ reversed the antinociception of PEMM. Phytochemical analyses revealed the presence of several antinociceptive-bearing bioactive compounds, such as triterpenes and volatile compounds like oleoamide and palmitic acid. The presence of low flavonoids, such as gallocatechin and epigallocatechin, saponins and tannins in PEMM might synergistically contribute to enhance the major compounds antinociceptive effect.

Conclusion: PEMM exerted a non-opioid-mediated antinociceptive activity at the central and peripheral levels via the inhibition of vanilloid receptors and glutamatergic system, and the activation of NO-mediated/cGMP-independent pathway. Triterpenes, as well as volatile oleoamide and palmitic acid, might be responsible for the observed antinociceptive activity of PEMM.

Keywords: Melastoma malabathricum, Crude methanol extract, Fraction, Antinociceptive activity, Mechanisms of antinociception, Non-opioid system, Vanilloid receptors, Glutamatergic system, NO-mediated/cGMP-independent pathway

\section{Background}

Pain is one of the most common manifestations of many diseases afflicting millions of people worldwide $[1,2]$. It is major symptom of various ailments that incessantly producing severe physical and psychological distress for many patients at the same time disrupting their quality of life $[3,4]$. In such situation, analgesics drugs are useful due to these agents ability to relieve pain without producing a loss of consciousness. Currently, three major classes of drugs are used in the pharmacological therapy of pain, namely non-steroidal anti-inflammatory drugs (NSAIDs), opioids and analgesic adjuvants, which target different components of the peripheral and central nervous system [5-7]. Unfortunately, the undesirable adverse effects such as gastrointestinal damage, renal toxicity, sedation, tolerance and respiratory depression, always overshadowed those drugs effectiveness and limited their uses $[8,9]$. Due to this issue, peoples living in many developing countries in particular have been turning to natural products, particularly, those derived from medicinal plants/herbal medicines, as an alternative sources of pain-relieving agents $[10,11]$. The application of plant-based natural products in the treatment of various ailments have been associated with the assumption that natural products are at least safe for consumption and cheaper than syntheticallydeveloped drugs $[12,13]$.

One of the plants that have been traditionally used to treat pain is Melastoma malabathricum L. (family Melastomaceae) [14]. Locally known to the Malay as "Senduduk", M. malabathricum has been used in the Malay traditional medicines to treat ailments such as stomach ulcers, dysentery and diarrhoea, those associated with pain (i.e., toothache and stomachache), to accelerate wound healing, for post-natal care and prevention of scars from small pox infection, and postpartum remedy [15-19]. Scientifically, the leaves of M. malabathricum have been reported to exert no acute toxicity [20] and, antibacterial [20,21], antiviral [20], antioxidant [22], cytotoxic [22], anti-inflammatory [23, 24], anticoagulant [25], antiulcer [26], antidiarrheal [20], antinociceptive $[16,24]$ and antipyretic [24] activities.

In order to justify the present antinociceptive study, it is important to highlight on the previous reports related to the antinociceptive activity of $M$. malabathricum. In the two previous reports, the aqueous [24] and ethanol [16] extracts of the leaves were used and only the role of opioid receptors in modulating those extracts antinociceptive activity was investigated. In addition, we have recently published on the central and peripheral antinociceptive potential of methanol extract of $M$. malabathricum (MEMM), and reported on the involvement of vanilloid receptors, glutamatergic system and NO-mediated/cGMPindependent pathway, but not opioid receptors, in the modulation of MEMM antinociceptive activity [27]. Taking these facts into account, the present study was designed to determine the antinociceptive potential of several fractions derived from MEMM, namely petroleum ether- (PEMM), ethyl acetate- (EAMM,) and aqueous- (AQMM) extract, and to determine the mechanisms of antinociception exhibited by the most effective partition using various animal models. Briefly, the fractions were screened using the acetic acid-induced abdominal constriction test to select the most potent fraction. The most potent fraction (in this case PEMM) were then tested against the hot plate- and 
formalin-induced paw licking-test to establish its antinociceptive profile and subjected to further investigation on the possible mechanisms of action involving the role of opioid and vanilloid receptors, glutamate system and nitric oxide/cyclic guanosine phosphate (NO/cGMP) pathway.

\section{Methods}

\section{Plant collection}

The leaves of M. malabathricum, collected and certified by a botanist from the Institute of Bioscience (IBS), Universiti Putra Malaysia (UPM), Serdang, Selangor, Malaysia. A voucher specimen (ACP0017) has been deposited at the Herbarium of the Laboratory of Natural Products, IBS, UPM, Malaysia.

\section{Preparation of methanol extract of Melastoma malabathricum (MEMM) leaves}

This procedure was performed as described in detailed by Zakaria et al. [27]. Briefly, $500 \mathrm{~g}$ of matured leaves that have been air-dried for 1-2 weeks at room temperature $\left(27 \pm 2{ }^{\circ} \mathrm{C}\right)$ were grinded into powder form. The leaves were soaked in methanol in the ratio of 1:20 $(\mathrm{w} / \mathrm{v})$ for $72 \mathrm{~h}$. These procedures were repeated three (3) times using the same residue. After each soaking, the supernatant was filtered using steel filter, cotton wools and Whatman no. 1 filter papers, and the supernatant collected from each extraction was pooled together. This supernatant was then subjected to evaporation process using a rotary evaporator at $40{ }^{\circ} \mathrm{C}$ under reduced pressure.

\section{Preparation of fractions from MEMM}

The petroleum ether (PEMM), ethyl acetate (EAMM) and aqueous (AQMM) fractions were obtained from crude dried MEMM via the standard solvent partitioning methods as previously described by Sowndhararajan et al. [28]. Briefly, dried MEMM (20 g) was dissolved in $1000 \mathrm{~mL}$ of methanol (1:20; w/v) followed by the addition of $200 \mathrm{~mL}$ of distilled water. The suspension was then added with $700 \mathrm{~mL}$ of petroleum ether and shake thoroughly before left for $24 \mathrm{~h}$ to settle down into two immiscible layers wherein the lower layer (petroleum ether supernatant) was collected while the upper layer (aqueous methanol supernatant) was subjected to repeat extraction using new petroleum ether for another two times. On the other hand, the undissolved upper layer was further partitioned using ethyl acetate according to the procedures described for petroleum ether. All petroleum ether and ethyl acetate supernatants were collected and pooled together before being rotary evaporated. Each supernatant was evaporated under reduced pressure (204 Mbar) and controlled temperature $\left(40{ }^{\circ} \mathrm{C}\right)$ using a vacuum rotary evaporator (Buchi Rotavapor ${ }^{\circ}$ R210, Switzerland). In contrast, the remaining undissolved supernatant, which represents the aqueous supernatant, was collected and subjected to the freeze-drying process.

\section{Phytochemical screening of the most effective fraction (PEMM)}

The phytochemical screening of the most effective fraction (PEMM), which was determined following the antinociceptive evaluation using the abdominal constriction test, was performed according to the standard screening tests described by Ikhiri et al. [29] but adopted by Kamisan et al. [30]. The respective test, performed to detect flavonoids, saponins, tannins, triterpenes, steroids and alkaloids, was carried out based on the $100 \mathrm{mg}$ of crude extract or fractions.

\section{HPLC analysis of the most effective fraction (PEMM) at various wavelengths}

The HPLC profile of MEMM has been published by Mamat et al. [31]. The HPLC profile of the most effective fraction (PEMM) was established according to the same methods [31]. Briefly, $10 \mathrm{mg}$ of the respective fraction was suspended in $1 \mathrm{ml}$ methanol and then filtered using the $0.45 \mu \mathrm{m}$ pore size membrane filter. The filtered extract was then analysed using the HPLC system consisting of the Waters Delta 600 with 600 Controller linked to a Waters 996 photodiode array detector (Milford, MA, USA) and a $5 \mu \mathrm{m}$ column (Phenomenex Luna; $4.6 \mathrm{~mm}$ i.d. $\times 250 \mathrm{~mm}$ ) (Torrance, CA, USA). The sample was eluted using a solvent system consisting of $0.1 \%$ aqueous formic acid (tagged as $\mathrm{A}$ ) and acetonitrile (tagged as B). The early condition was $95 \% \mathrm{~A}$ and $5 \% \mathrm{~B}$ with a linear gradient attaining $25 \% \mathrm{~B}$ at $t=12 \mathrm{~min}$. This condition was retained for $10 \mathrm{~min}$ wherein at $t=22 \mathrm{~min}$, B was decreased to $15 \%$, which was then retained until $t$ $=30 \mathrm{~min}$. The programme returned to the early solvent composition at $t=35 \mathrm{~min}$. Throughout the analysis period, the flow rate was maintained at $1.0 \mathrm{ml} / \mathrm{min}$ while the injection volume was maintained at $10 \mu \mathrm{l}$. The column oven was positioned at $27^{\circ} \mathrm{C}$ and the eluent was monitored at 210, 254, 280, 300, 330 and $366 \mathrm{~nm}$. The retention time and UV spectra of major peaks were recorded and then analyzed. PEMM was then spiked with a list of flavonoid-based compounds (served as the standard), namely pinostrobin, hesperetin, flavanone, 4,5,7trihydroxy flavanone, 2,4,4'-trihydroxy chalcone, quercitrin, dihydroquercitin, fisetin, quercetin, rutin, quercitrin, naringenin, silibinin, and genistein using the same solvent system to detect their presence in the respective fraction. The HPLC analysis was carried out in the Laboratory of Phytomedicine, Medicinal Plants Division, Forest Research Institute of Malaysia (FRIM), Kepong, Malaysia. 


\section{UHPLC-ESI Profile of the most effective fraction (PEMM)}

The UHPLC system was performed on a Dionex 3000 UHPLC system acquired from Thermo Fisher Scientific (USA) that consists of an auto-sampler equipped with a column oven, a tray compartment cooler, and a binary pump with built-in solvent degasser [32]. Samples $(10 \mu \mathrm{L})$ were injected and the chromatographic separation was performed on a BEHC18UHPLC column, $100 \mathrm{~mm} \times 2.5$ $\mu \mathrm{m}, 1.7 \mu \mathrm{m}$ (WATERS) at a flow rate of $0.3 \mathrm{~mL} / \mathrm{min}$. The mobile phases used were (A) $0.1 \%$ formic acid in water and (B) $0.1 \%$ formic acid in acetonitrile. The separation was conducted using the following multistep gradient: initial conditions ( $t=0 \mathrm{~min}$ ) were $90 \% \mathrm{~A}$ and $10 \% \mathrm{~B}$ with a linear gradient reaching $15 \% \mathrm{~B}$ at $t=3 \mathrm{~min}$. The gradient was then increased to $50 \% \mathrm{~B}$ in the next $7 \mathrm{~min}(t=$ $10 \mathrm{~min}$ ) and further increased to $90 \% \mathrm{~B}$ for the next $2 \mathrm{~min}$ $(t=12 \mathrm{~min})$. Finally, the programme was returned to the initial solvent composition at $t=17 \mathrm{~min}$ for the next analysis. The UHPLC system was coupled to a Linear Ion Trap Orbitrap mass spectrometer ( $Q$ Exactive) from Thermo Fisher Scientific (USA) equipped with an electrospray ionization (ESI) source. The mass detection was performed in a range of $150-1500 \mathrm{~m} / z$. The ESI source was operated in negative ion mode under the following specific conditions: source voltage: $3.2 \mathrm{kV}$; sheath gas: 35 arbitrary units; auxiliary gas: 15 arbitrary units; sweep gas: 10 arbitrary units; and capillary temperature: $320{ }^{\circ} \mathrm{C}$. Nitrogen (>99.98\%) was employed as sheath, auxiliary, and sweep gas. Instrument control and data acquisition were performed with Chameleon 6.8 software and Xcalibur 2.2 software (Thermo Fisher Scientific). The UHPLC-ESI analysis was carried out in the Laboratory of Phytochemistry Unit, Herbal Medicine Research Centre, Institute for Medical Research, Jalan Pahang, 50588 Kuala Lumpur, Malaysia.

\section{GC-MS analysis of MEMM and PEMM}

GC-MS analysis of MEMM and PEMM were performed using the Agilent GC system (Model no. Agilent 19091S-433) attached to the gas chromatographinterfaced to a mass spectrometer detector (GC-MSD) equipped with a HP-5MS silica capillary column $(30.0 \mathrm{~m}$ X $250 \mu \mathrm{m}$ X $0.25 \mu \mathrm{m}$ nominal), composed of 5\% phenyl methyl siloxane. For GC-MS detection, an electron ionization system with ionizing energy of $70 \mathrm{eV}$ was used. Helium gas (99.999\%) was used as the carrier gas at constant flow rate of $1 \mathrm{~mL} / \mathrm{min}$ and an injection volume of $1 \mu \mathrm{L}$ was employed (split ratio of 10:1); mode Split-Splitless Inlet; Injector temperature $250{ }^{\circ} \mathrm{C}$ (pressure $10.39 \mathrm{psi}$ ); Ion-source temperature $280{ }^{\circ} \mathrm{C}$. The oven temperature was programmed from $100{ }^{\circ} \mathrm{C}$ (isothermal for $2 \mathrm{~min}$ ) and maximum oven configuration at $325^{\circ} \mathrm{C}$, with an increase of $10{ }^{\circ} \mathrm{C} / \mathrm{min}$, to $200^{\circ} \mathrm{C}$, then $5^{\circ} \mathrm{C} / \mathrm{min}$ to $280{ }^{\circ} \mathrm{C}$, ending with a $9 \mathrm{~min}$ isothermal at $280{ }^{\circ} \mathrm{C}$. Mass spectra were taken at $70 \mathrm{eV}$; a scan interval of $0.5 \mathrm{~s}$ and fragments from 45 to $450 \mathrm{Da}$. Total GC running time was $35.50 \mathrm{~min}$. The relative \% amount of each component was calculated by comparing its average peak area to the total areas, software adopted to handle mass spectra and chromatograms was a Turbomass. For identification of compounds, the interpretation on mass spectrum GC-MS was conducted using the database of National Institute Standard and technology (NIST) having more than 62,000 patterns. The spectrum of the unknown component was compared with the spectrum of the known components stored in the NIST library. The name, molecular weight and structure of the components of the test materials were ascertained.

\section{Drugs and chemicals}

The following reagents and drugs were used: methanol, petroleum ether, and ethyl acetate (Fischer Scientific, UK); dimethyl sulfoxite (DMSO), formalin, acetic acid, morphine sulphate, acetylsalicylic acid (ASA), naloxone (NLX), capsaicin, glutamate, capsazepine, L-arginine (L-arg), $\mathrm{N}^{\mathrm{G}}$-nitro-L-arginine methyl esters (L-NAME) and methylene blue (MB) (Sigma, USA). The drugs were prepared by dissolving them in the saline solution. The MEMM was dissolved in the vehicle (10\% DMSO) just before used. All solutions were administered in the volume of $10 \mathrm{~mL} / \mathrm{kg}$.

\section{Animals}

Male Sprague Dawley (SD) rats (180-200 gm; 8-10 weeks old) and male ICR mice (25-30 g; 5-7 weeks old) were purchased from Che Nur Supplier, Selangor, Malaysia. The animals were kept under room temperature $(27 \pm$ $2{ }^{\circ} \mathrm{C} ; 70-80 \%$ humidity; 12 hrs light/darkness cycle) in the Animal Holding Unit, Kulliyyah of Allied Health Sciences, International Islamic University Malaysia (IIUM), Pahang, Malaysia and were supplied with food and water ad libitum up to the beginning of the experiments. Each rats and mice were only used once. The animals were handled in accordance with the current IIUM guidelines for the care of laboratory animals and the ethical guidelines for investigations of experimental pain in conscious animals [33]. The procedures in the present study were approved by the Animal Ethics Committee of International Islamic University Malaysia [IIUM / IACUC Approval / 2016/ (9) (58)] and were performed in accordance with the Integrated Centre for Research of Animal Care and Use (ICRACU) guidelines. The number of animals and intensity of noxious stimuli used were minimum and just at the necessary amount to demonstrate the consistent effects of the treatments. In all experiments, data were collected by a blinded, randomized and controlled design. All the experiments were conducted between the 0930 and $1830 \mathrm{~h}$ to minimize the effects of environmental 
changes. All efforts were made to minimize animal suffering and to reduce the number of animals used.

\section{Acute toxicity study}

Acute toxicity study was performed according to the guideline for testing of chemicals by adopting the OECD No. 423 procedure [34]. According to this procedure, the acute oral toxicity study was carried out using the fixed dose approaches. Rats were divided into two groups $(n=10)$ and fasted overnight. One group was then treated with a single dose of $5000 \mathrm{mg} / \mathrm{kg}$ PEMM while the other group was given vehicle (10\% DMSO) $(10 \mathrm{~mL} / \mathrm{kg})$ by gavage. Each animal was monitored at least once through the first $30 \mathrm{~min}$ after the test solutions administration, intermittently during the first $24 \mathrm{~h}$ and daily afterward for 14 days. Food and water were supplied ad libitum. The mortality, body weight and behavioral screening were documented daily within the 14 days observation. Any survived rats were euthanized and subjected to the macroscopic analysis. The vital organs were collected, weighted and then fixed in 10\% formalin for microscopic analysis.

\section{Antinociceptive studies \\ Acetic acid-induced abdominal constriction test}

The acetic-acid-induced abdominal constriction test was performed according to the method described by Zakaria et al. [26] with slight modification. Male ICR mice were placed in the $10 \mathrm{~L}$ glass beaker as observation chamber for $20 \mathrm{~min}$ prior to the experiment to adapt to their surroundings. The mice $(n=6)$ were pre-treated orally (p.o) with $10 \%$ DMSO (negative control), $100 \mathrm{mg} / \mathrm{kg}$ ASA (positive control), or PEMM, EAMM, or AQMM $(100,250$, and $500 \mathrm{mg} / \mathrm{kg}$ ). $60 \mathrm{~min}$ after the respective test solution administration, the mice were injected via intraperitoneal (i.p) route with $0.6 \%$ acetic acid $(10 \mathrm{~mL} / \mathrm{kg})$. The animals were immediately placed individually into the observation chamber and $5 \mathrm{~min}$ were allowed to elapse. The abdominal constriction resulting from the injection of acetic acid consists of constrictions of the abdominal together with a stretching of at least one hind limb. The number of abdominal constrictions produced in these animals was counted cumulatively for $25 \mathrm{~min}$. Antinociceptive activity, indicated by the reduction in the mean of the number of abdominal constrictions in the test groups compared to the control group, was calculated as the percentage inhibition of abdominal constrictions (percentage of inhibitory level) using the following formula: (mean of [(control - test group)/control group] X 100\%).

\section{Hot plate test}

The hot-plate test was used to measure response latency according to the method described by Zakaria et al. [26] with some modifications. The temperature of the metal surface (Hotplate Analgesia Meter, Columbus Instruments, Model: 144-E52) was set at $50 \pm 0.2{ }^{\circ} \mathrm{C}$. The time(s) elapsed between placement until the occurrence of discomfort reactions (licking paws or jumping) was recorded as the response latency time. The mice were selected a day prior to the test on the basis of their reactivity, and only those with response latencies of $5-7 \mathrm{~s}$. were used in the study. The mice $(n=6)$ were pre-treated (p.o) with 10\% DMSO (negative control), $5 \mathrm{mg} / \mathrm{kg}$ morphine (positive control or reference drug), or PEMM (100, 250, and $500 \mathrm{mg} / \mathrm{kg}$ ). Sixty minutes after the respective test solution administration, the mice were placed on the heated metal surface with the arbitrary cutoff time of $20 \mathrm{~s}$. This cut-off time was adopted and defined as complete analgesia as well as to avoid tissue injury. The latency to a discomfort reaction was recorded before and at $60,90,120,150,180,210 \mathrm{~min}$ after the p.o. administration of test solutions. The prolongation of the latency times compared with the values of the controls was used for statistical comparison.

\section{Formalin-Induced paw licking test}

The formalin test was performed as described by Zakaria et al. [26] but with slight modifications. Pain was induced by injecting $50 \mu \mathrm{L}$ of $5 \%$ formalin in the intraplantarly (i.pl.) into the ventral surface of the right hind paw. Rats $(n=6)$ were administered p.o. with $10 \%$ DMSO (negative control), $5 \mathrm{mg} / \mathrm{kg}$ morphine or $100 \mathrm{mg} / \mathrm{kg}$ ASA (both act as the positive controls), or PEMM (100, 250, and $500 \mathrm{mg} / \mathrm{kg}$ ) $60 \mathrm{~min}$ prior to the formalin injection. Immediately after the phlogistic agent administration, the rats were individually placed into $10 \mathrm{~L}$ glass beaker as observation chamber. The amount of time that the animal spent licking, or biting the injected paw, considered as an indicator of pain, was recorded for the duration of $30 \mathrm{~min}$ in two phases, known as the early $(0-5 \mathrm{~min})$ and late (15-30 min) phases.

\section{Analysis of the possible mechanism of antinociceptive action of PEMM \\ Investigation on the role of vanilloid receptors using the capsaicin-induced paw licking test}

To investigate the role of vanilloid or TRPV1 receptors in the modulation of MEMM antinociceptive action, the procedure described by Mohd Sani et al. [35] was adopted with slight modifications. Rats were pre-treated orally with 10\% DMSO, capsazepine (Capz, $0.17 \mathrm{mmol} / \mathrm{kg}$ ) or PEMM $(100,250$, and $500 \mathrm{mg} / \mathrm{kg}) 60 \mathrm{~min}$ before capsaicin $(1.6 \mathrm{ug} /$ paw, $20 \mu \mathrm{L})$ administration via i.pl. route into the ventral surface of the right hind paw. Immediately after the phlogistic agent administration, the rats were individually placed in a transparent glass cage observation chamber and observed individually for $5 \mathrm{~min}$. The amount of time the animals spent licking the injected 
paw was recorded with a chronometer and was considered as an indication of nociception.

\section{Investigation on the role of glutamatergic system using the glutamate-induced paw licking test}

To study the role of glutamatergic system in the modulation of PEMM antinociceptive action, the procedure described by Mohd Sani et al. [35] was performed with slight modifications. Rats were pre-treated orally with $10 \%$ DMSO, $100 \mathrm{mg} / \mathrm{kg}$ ASA or PEMM (100, 250, and $500 \mathrm{mg} / \mathrm{kg}$ ) $60 \mathrm{~min}$ prior to glutamate injection. A volume of $20 \mu \mathrm{L}$ of glutamate $(10 \mu \mathrm{mol} / \mathrm{paw}$; in normal saline) was injected via i.pl route into the ventral surface of the right hind paw. Immediately after the phlogistic agent administration, the rats were individually placed in a transparent glass cage observation chamber and observed individually from 0 to $15 \mathrm{~min}$. The amount of time the animals spent licking or biting the injected paw was recorded with a chronometer and was considered as an indicator of nociception.

\section{Investigation on the involvement of opioid receptors system} using the hot plate and formalin-induced paw licking tests

To determine the role of opioid receptors in the modulation of PEMM antinociceptive activity, a separate procedure described by Mohd Sani et al. [35] was adopted with slight modifications. Four groups of animals $(n=6)$ were pre-treated (i.p.) with a non-selective opioid antagonist, naloxone $(5 \mathrm{mg} / \mathrm{kg}$; i.p.) for $15 \mathrm{~min}$ followed by the oral administration of $10 \%$ DMSO or PEMM $(500 \mathrm{mg} / \mathrm{kg})$. Sixty minutes later, the animals were subjected to the hot plate test and formalin test.

\section{Investigation on the involvement of nitric oxide/cyclic- guanosine monophosphate (NO/cGMP) pathway using the abdominal constriction test}

To determine the role of nitric oxide/cyclic-guanosine monophosphate $(\mathrm{NO} / \mathrm{cGMP})$ pathway in the modulation of PEMM antinociceptive activity, the method described by Mohd Sani et al. [35] was adopted with slight modifications. Mice $(n=6)$ were pre-treated with $20 \mathrm{mg} / \mathrm{kg}$ L-arginine, L-NAME, MB, or their respective combination (L-arginine with L-NAME or L-arginine with $\mathrm{MB}$ ) followed 5 min later by treatment with $10 \%$ DMSO or PEMM (500 mg/kg), respectively. Sixty minutes after the administration of test solutions, the mice were injected (i.p) with $0.6 \%$ acetic acid.

\section{Statistical analysis}

The data from the antinociceptive studies $(n=6)$ were expressed as means \pm standard error of mean (S.E.M) and analyzed by one or two-way analysis of variance (ANOVA) followed by the respective Dunnett's post hoc test, or Bonferroni post-test, unless otherwise stated.
The different between means of treated and a control group was considered significant at $P<0.05$. The $\mathrm{ED}_{50}$ (effective dose producing a $50 \%$ inhibition in relative to control value) value for all partitions following the abdominal constriction study were determined using the GraphPad Prism Software 5.0 (GraphPad Prism, USA). The calculated $\mathrm{ED}_{50}$ and percentages of inhibition were used to determine the most effective partition to be used in the further antinociceptive studies.

\section{Results}

\section{Phytochemical screening of PEMM}

The crude MEMM has been reported elsewhere to contain flavonoids, triterpenes, tannins, saponins and steroids. In comparison to MEMM, PEMM showed strong presence of triterpenes and steroids but low presence of flavonoids, tannins and saponins. No alkaloids were detected in MEMM or PEMM (Table 1).

\section{HPLC profiling of PEMM at different wavelength}

The HPLC profile of PEMM measured at the wavelength of 254 and $366 \mathrm{~nm}$ is shown in Fig. 1, respectively. At $254 \mathrm{~nm}$, three major peaks were detected in PEMM at the retention time (RT) of 18.946, 20.608 and $23.063 \mathrm{~min}$ while at $366 \mathrm{~nm}$ only two major peaks were detected in PEMM at the retention time (RT) of 20.630 and $23.064 \mathrm{~min}$.

Further analysis via spiking with standard flavonoidbased compounds available in our laboratory collection demonstrated that none of the pure flavonoid-based standards (e.g. pinostrobin, hesperetin, flavanone, 4,5,7-trihydroxy flavanone, 2,4,4'-trihydroxy chalcone, quercitrin, dihydroquercitin, fisetin, quercetin, rutin, quercitrin, naringenin, silibinin, and genistein) were detected in PEMM. Figure 2 show that, at least, rutin's peak, which is the closest to one of the peak of PEMM, did not perfectly match the peak with RT of $20.630 \mathrm{~min}$.

Table 1 Phytochemical screening of semi-purified PEMM and comparison to crude MEMM

\begin{tabular}{llc}
\hline Class of Compounds & \multicolumn{2}{c}{ Samples } \\
\cline { 2 - 3 } & MEMM ${ }^{a}$ & PEMM \\
\hline Flavonoids & +++ & + \\
Triterpenes & ++ & ++ \\
Tannins & ++ & + \\
Saponins & ++ & + \\
Steroids & +++ & +++ \\
Alkaloid & - & -
\end{tabular}

For flavonoids, tannins, triterpene and steroids - + : weak colour; ++ : mild colour; +++ : strong colour

For saponins -+: $1-2 \mathrm{~cm}$ froth; $++: 2-3 \mathrm{~cm}$ froth; $+++:>3 \mathrm{~cm}$ froth For alkaloids: -+ : negligible amount of precipitate; ++ : weak precipitate; +++ : strong precipitate

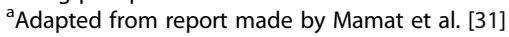




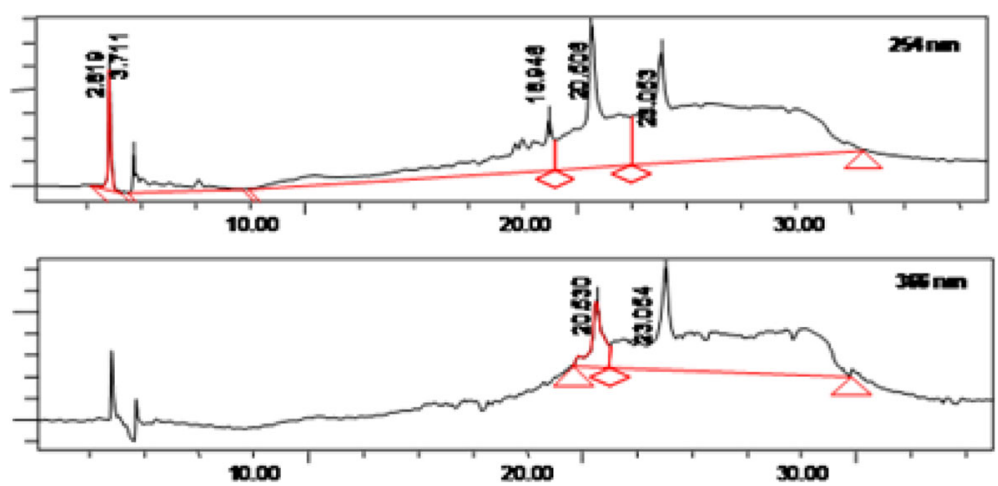

Fig. 1 The HPLC profile of PEMM at $254 \mathrm{~nm}$ and $366 \mathrm{~nm}$

\section{UHPLC-ESI profiling of PEMM}

The fraction of $M$. malabathricum, PEMM, was analyzed based on the accurate mass data of the molecular ions, in which ions detected were tentatively identified by their generated molecular formula using the data analysis software (Xcalibur) that provided list of possible elemental formulas. These findings were compared together with the standard flavonoids available in the laboratory and further supported by the thorough survey of the literature. The widely accepted accuracy threshold for confirmation of elemental compositions was established at $5 \mathrm{ppm}$. The UHPLC-ESI analysis of PEMM revealed the presence of only two very small peaks indicating the presence of very small concentration of phenolic compounds, which have been identified as gallocatechin and epigallocatechin (Fig. 3).

\section{GC-MS profiles of MEMM and PEMM}

GC-MS spectra profile of crude extract (MEMM) and the most effective fraction (PEMM) are presented in the Fig. 4a and b while the identified volatile compounds are presented in Tables 2 and 3, respectively. Twenty nine volatile compounds were identified in MEMM with oleic acid amide (43.99\%), 3-methylquinoline (7.84\%) and propanoic acid $(5.78 \%)$ being the three major volatile compounds (Table 2). Table 3 shows the volatile compounds present in PEMM wherein four major volatile compounds were detected, namely, oleic acid amide (11.54\%), palmitinic acid (6.95\%), methyl-25-homocholesterol (10.06\%), linolenic acid methyl ester (5.69\%) and phthalic acid $(5.90 \%)$.

\section{Acute toxicity effect of PEMM}

All animals, either those that received PEMM or vehicle, exhibited a rise in body weight at weeks 1 and 2 in comparison to day 0 . No changes in the behavioral pattern, mortality, or food and water intake behavior were detected among the animals were detected during the duration of experimentation. Moreover, there is no significant changes detected in the relative weight of vital organs, which was supported by the microscopic analysis that shows no signs of toxicity (data not shown). Based on these findings, PEMM was suggested to possess an $\mathrm{LD}_{50}$ that is greater than $5000 \mathrm{mg} / \mathrm{kg}$ body weight.

\section{Antinociceptive profile of fractions assessed using the abdominal constriction test}

The antinociceptive profile of PEMM, EAMM and AQMM assessed by the acetic acid-induced abdominal constriction test in mice is shown in Fig. 5. Pre-administration of

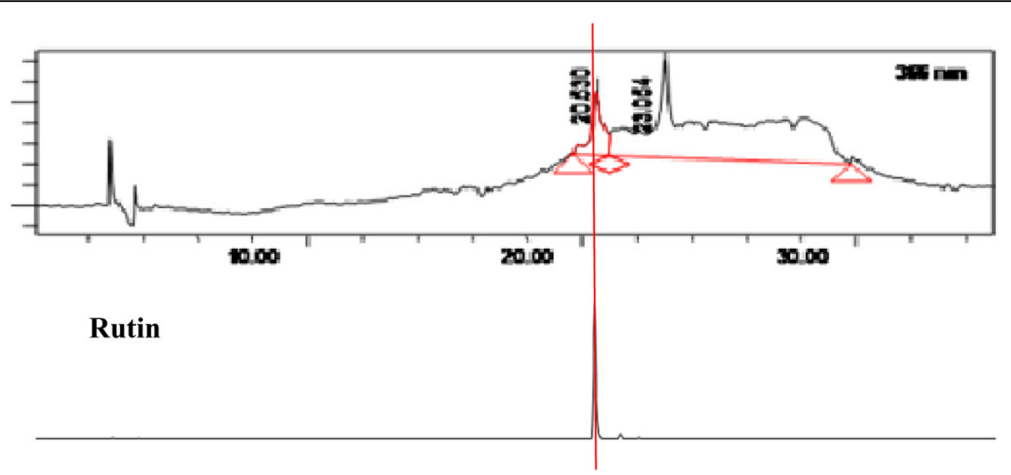

Fig. 2 The HPLC profile of PEMM demonstrated the absence of rutin 


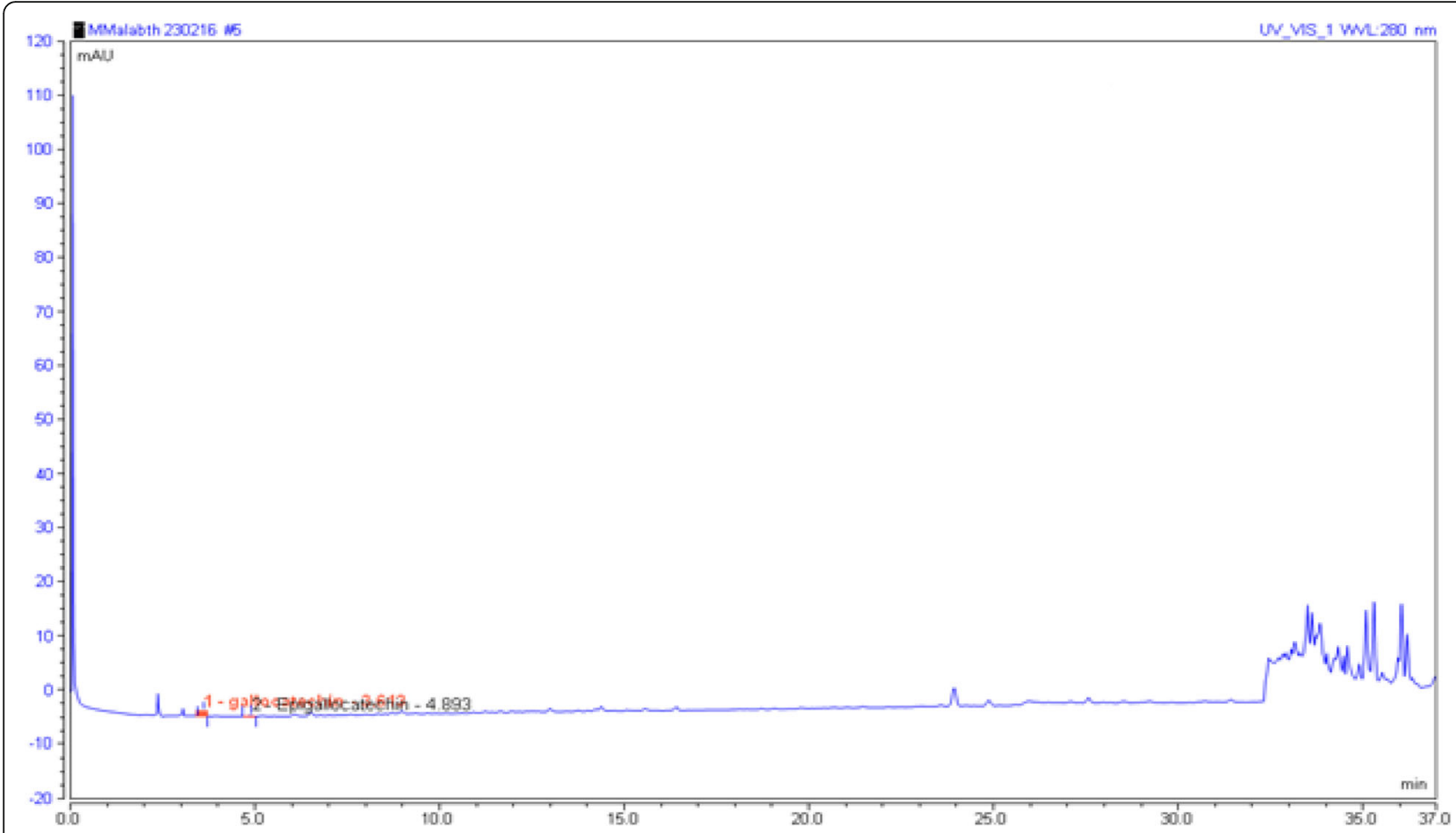

Fig. 3 The HPLC-ESI profile of PEMM demonstrated the presence of low content of flavonoid-based compounds, namely gallocatechin and epigallocatechin

PEMM, EAMM and AQMM (100, 250 and $500 \mathrm{mg} / \mathrm{kg}$, p.o) significantly $(p<0.05)$ reduced the number of abdominal writhes induced by acetic acid in a dose-dependent manner. From the data obtained, PEMM and EAMM exerted almost similar antinociceptive efficacy but based on the calculated $\mathrm{ED}_{50}$ values, PEMM $\left(\mathrm{ED}_{50}=119.5 \mathrm{mg} /\right.$ $\mathrm{kg}$ ) was considered to be more effective than EAMM $\left(\mathrm{ED}_{50}=125.9 \mathrm{mg} / \mathrm{kg}\right)$. Thus, PEMM was chosen for further antinociceptive studies.

\section{Antinociceptive profile of PEMM assessed using the hot-plate test}

The antinociceptive profile of PEMM assessed using the hot plate test is shown in Table 4. PEMM demonstrated a significant $(p<0.05)$ antinociceptive activity in a dose-dependent manner indicated by the increase in the latency of time spend on the thermal-induced hot plate apparatus. PEMM, at $100 \mathrm{mg} / \mathrm{kg}$, was significantly effective only at the interval of 60 and $90 \mathrm{~min}$ after the extract administration while, at the doses of 250 and $500 \mathrm{mg} / \mathrm{kg}$, PEMM exerts its antinociceptive activity until the end of the experiment. Interestingly, the antinociceptive efficacy of PEMM was comparable to that of $5 \mathrm{mg} / \mathrm{kg}$ morphine (a reference antinociceptive drug).

\section{Antinociceptive profile of PEMM assessed using the formalin-induced paw licking test}

The antinociceptive potential of PEMM against the formalin-induced paw licking test is shown in Fig. 6a and b. Pre-treatment with PEMM caused significant $(p<$ $0.05)$ reduction in the latency of time spends to lick the formalin-injected paw in a dose-dependent manner. Interestingly, the ability of PEMM to attenuate nociception induced by formalin can be seen in both the early and late phases, a characteristic also seen with $5 \mathrm{mg} / \mathrm{kg}$ morphine, but not $100 \mathrm{mg} / \mathrm{kg}$ ASA.

\section{Mechanisms of antinociceptive activity of PEMM Involvement of vanilloid receptors in the antinociceptive activity of PEMM}

From the results obtained, PEMM, at all doses, caused a significant $(p<0.05)$ and dose-dependent inhibition of the capsaicin-induced neurogenic nociception (Fig. 7). Administration of capsazepine (vaniloid receptors' antagonist), at $0.17 \mathrm{mmol} / \mathrm{kg}$, significantly $(p<0.05)$ produced approximately $55.3 \%$ inhibition against capsaicin-induced nociception, which was comparable to that of $500 \mathrm{mg} / \mathrm{kg}$ PEMM (60.5\%).

\section{Involvement of glutamatergic system in the antinociceptive activity of PEMM}

From the results obtained, all doses of PEMM significantly $(p<0.05)$ reduced the latency of paw licking due to glutamateinduced nociception (Fig. 8). Administration of $100 \mathrm{mg} / \mathrm{kg}$ ASA significantly $(p<0.05)$ produced approximately $74.1 \%$ inhibition against glutamate-induced nociception, which was comparable to that of $500 \mathrm{mg} / \mathrm{kg}$ PEMM (66.2\%). 

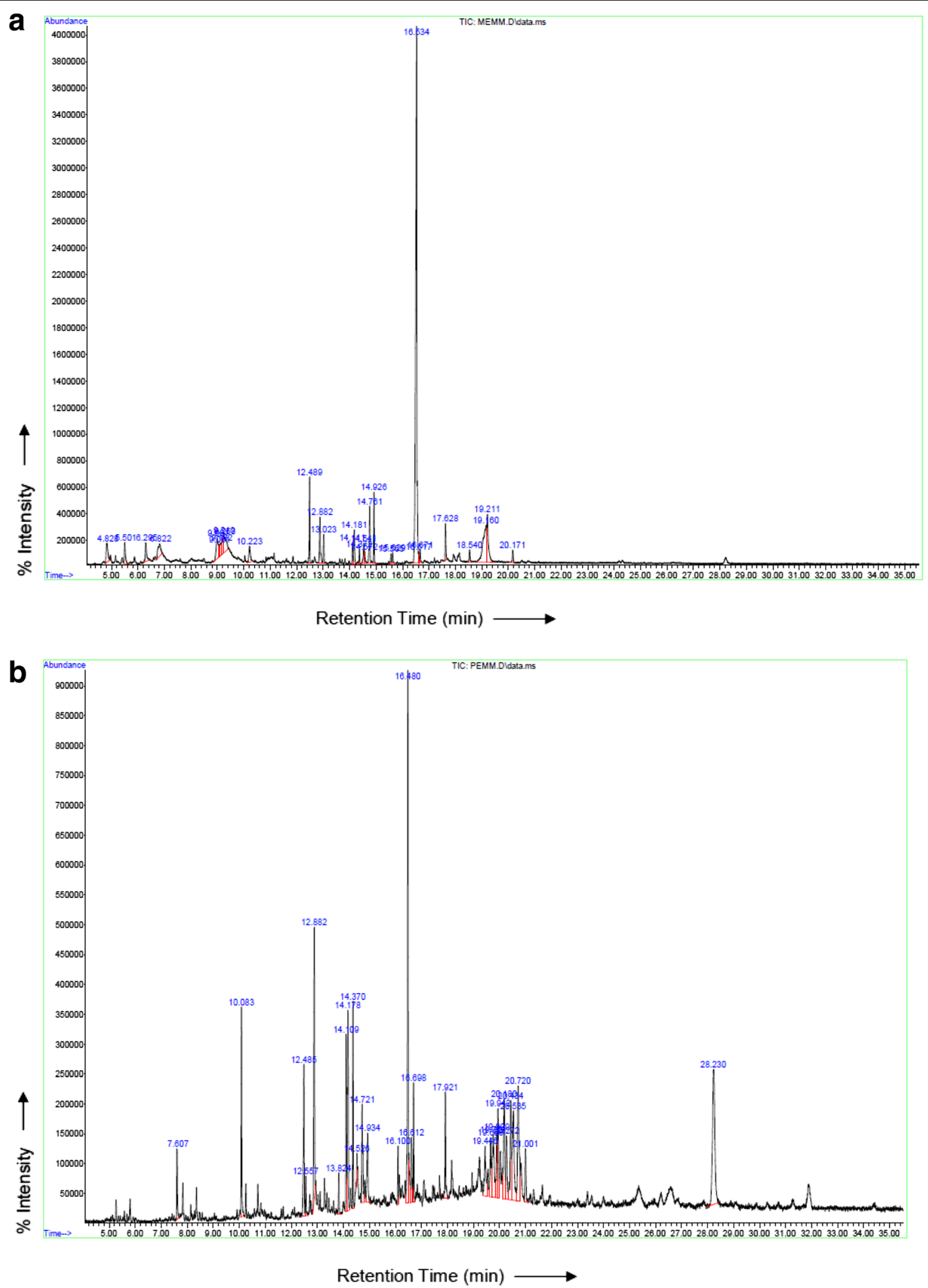

Fig. 4 a The GCMS profile of MEMM. $\mathbf{b}$ The GCMS profile of PEMM 
Table 2 GC-MS profile of the possible volatile compounds presence in MEMM

\begin{tabular}{|c|c|c|c|}
\hline No & $\begin{array}{l}\text { Retention } \\
\text { Time (RT) }\end{array}$ & $\begin{array}{l}\text { Relative Area } \\
\text { Percentage } \\
\text { (Area \%) }\end{array}$ & Identified Compounds \\
\hline 1. & 4.83 & 2.28 & 2-Furancarboxaldehyde \\
\hline 2. & 5.50 & 1.53 & a-L-Galactopyranoside \\
\hline 3. & 6.30 & 1.71 & 2-Methyl-L-mannomethylpyranoside \\
\hline 4. & 6.83 & 2.28 & Pyrogallic acid \\
\hline 5. & 9.00 & 2.68 & a-D-Glucopyranoside \\
\hline 6. & 9.06 & 0.58 & Methyl $\beta$-d-Galactopyranoside \\
\hline 7. & 9.13 & 1.18 & $\beta$-D-Glucopyranoside \\
\hline 8. & 9.22 & 1.87 & $\beta$-D-Ribopyranoside \\
\hline 9. & 9.25 & 2.82 & Galactopyranoside \\
\hline 10. & 10.22 & 1.62 & Pyridine \\
\hline 11. & 12.49 & 3.38 & Palmitic acid \\
\hline 12. & 12.88 & 2.88 & Palmitinic acid \\
\hline 13. & 13.03 & 1.26 & Myristic acid amide \\
\hline 14. & 14.11 & 0.87 & Linoleic acid \\
\hline 15. & 14.18 & 2.08 & Linolenic acid \\
\hline 16. & 14.37 & 0.56 & Stearic acid methyl ester \\
\hline 17. & 14.54 & 1.34 & Oleic acid \\
\hline 18. & 14.58 & 0.54 & Pentadecanoic acid \\
\hline 19. & 14.76 & 2.90 & Oleic acid amide \\
\hline 20. & 14.92 & 2.85 & $\mathrm{~N}$-tetradecanoic acid amide \\
\hline 21. & 15.56 & 0.40 & Heptanamide \\
\hline 22. & 15.63 & 0.52 & Erucylamide \\
\hline 23. & 16.54 & 43.99 & Oleic acid amide \\
\hline 24. & 16.63 & 0.56 & Pentanimidic acid \\
\hline 25. & 17.63 & 1.62 & Dodecanedoic acid-dimetyl ester \\
\hline 26. & 18.54 & 0.74 & 5,6-methylenedecane \\
\hline 27. & 19.16 & 7.84 & 3-Methylquinoline \\
\hline 28. & 19.21 & 5.78 & Propanoic acid \\
\hline 29. & 20.17 & 0.75 & Squalene \\
\hline \multicolumn{2}{|c|}{$\begin{array}{l}\text { Total Percentages } \\
\text { of Identified }\end{array}$} & 98.81 & \\
\hline
\end{tabular}

\section{Involvement of opioid receptors in the antinociceptive activity of PEMM}

The results show that naloxone failed to significantly interfere with the antinociceptive activity of PEMM in both the hot plate and formalin-induced paw licking tests (Table 4 and, Fig. $6 a$ and b, respectively).

\section{Involvement of NO/cGMP pathway in the antinociceptive activity of PEMM}

Figure 9a shows that: i) pre-treatment with $20 \mathrm{mg} / \mathrm{kg}$ L-arginine alone did not change the nociceptive intensity
Table 3 GC-MS profile of the possible volatile compounds presence in PEMM

\begin{tabular}{llll}
\hline No & $\begin{array}{l}\text { Retention } \\
\text { Time (RT) }\end{array}$ & $\begin{array}{l}\text { Relative Area } \\
\text { Percentage } \\
\text { (Area \%) }\end{array}$ & $\begin{array}{l}\text { Identified Compounds } \\
\text { 1. }\end{array}$ \\
2. & 10.61 & 1.42 & Tetradecanol \\
3. & 12.48 & 3.87 & Acrylic acid \\
5. & 12.88 & 6.95 & Palmitic acid \\
6. & 13.83 & 0.79 & Palmitic acid \\
7. & 14.11 & 3.12 & Diallylmethylsilane \\
8. & 14.18 & 5.69 & Linolenic acid methyl ester \\
9. & 14.37 & 3.46 & Stearic acid methyl ester \\
10. & 14.53 & 0.36 & Oleic acid \\
11. & 14.72 & 3.01 & Stearic acid \\
12. & 14.94 & 2.44 & 1-Nonadecene \\
13. & 16.10 & 1.03 & Arachidic acid methyl ester \\
14. & 16.48 & 11.54 & Oleoamide \\
15. & 16.62 & 1.53 & Trifluoroacetic acid \\
16. & 16.70 & 2.17 & hexanedioic acid Diisooctyl adipate \\
17. & 17.92 & 2.23 & 1,2-Benzenedicarboxylic acid \\
18. & 20.23 & 2.16 & 2-Acetyl-N-methylaniline \\
19. & 20.72 & 5.90 & Phthalic acid \\
20. & 21.00 & 1.69 & 2-methyl-Benzothiazole \\
21. & 28.23 & 10.06 & -Methyl-25-homochloesterol \\
Total Percentages & 73.07 & \\
of Identified & & \\
\hline & & & \\
\hline
\end{tabular}

induced by acetic acid; ii) pre-treatment with $20 \mathrm{mg} / \mathrm{kg}$ L-NAME alone significantly $(p<0.05)$ reduced the nociceptive effect of acetic acid, and; iii) a combination of L-arginine and L-NAME (L-arginine + L-NAME) alone reversed the antinociceptive effect of L-NAME when given alone. On the other hand, pre-challenging PEMM with: i) L-arginine significantly $(p<0.05)$ reversed, but did not block, the antinociceptive activity of PEMM; ii) L-NAME did not significantly change the antinociceptive intensity of PEMM, and; iii) a combination of (L-arginine + L-NAME) significantly $(p<0.05)$ reversed, but did not inhibit, the antinociceptive activity of PEMM.

Figure $9 \mathrm{~b}$ shows that: i) pre-treatment with $\mathrm{MB}$ alone induced significant $(p<0.05)$ antinociceptive activity, and; ii) pre-treatment with a combination of $\mathrm{L}$-arginine and $\mathrm{MB}$ (L-arginine $+\mathrm{MB})$ alone also demonstrated significant $(p<0.05)$ antinociceptive activity. Conversely, pre-challenging PEMM with $\mathrm{MB}$ or a combination of (L-arginine $+\mathrm{MB})$ failed to significantly $(p<0.05)$ change the antinociceptive intensity developed following earlier pre-treatment with MB. 


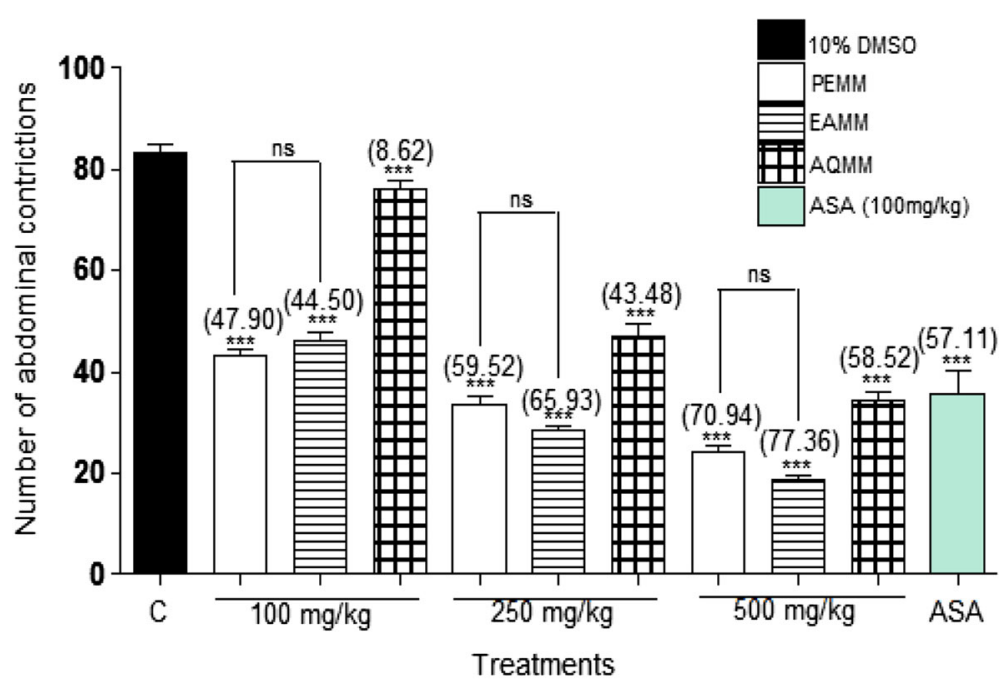

ID50 value (and their respective $95 \%$ confidence limit)

a) PEMM; $119.5 \mathrm{mg} / \mathrm{kg}(97.03-147.1 \mathrm{mg} / \mathrm{kg})$

b) EAMM: $125.9 \mathrm{mg} / \mathrm{kg}(109.9-144.1 \mathrm{mg} / \mathrm{kg})$

c) AQMM ; $352.6 \mathrm{mg} / \mathrm{kg}(311.1-399.4 \mathrm{mg} / \mathrm{kg})$

Fig. 5 Antinociceptive activity of PEMM, EAMM and AQMM assessed using the acetic acid-induced abdominal constriction test in mice

\section{Discussion}

In an attempt to contribute to the discovery of alternative/ new pain relieving agents with lack of unwanted side effects from medicinal plants, further antinociceptive investigations were performed on Melastoma malabathricum leaves. The present study was a continuation to our recently published report on the antinociceptive activity of methanol extract of M. malabathricum (MEMM) [27]. The justification for performing this experiment can be related to the phytoconstituents of methanol extract. Methanol is classified as a polar solvent due to the presence of hydroxyl $(-\mathrm{OH})$ group. However, there is also methyl group presence in methanol, which is sort of non-polar. Due to the presence of both polar and non-polar components in methanol, compounds that dissolve in water and oils equally well including their intermediates dissolves well in methanol. According to Ahmad et al. [36], the ability to extract various types of compounds using a solvent like methanol is parallel to the ability to increase extract's yield. Moreover, Caunii et al. [37] reported that methanol: i) can give higher concentrations of bioactive molecules from plants, and; ii) is the best solvents for extraction of different classes of phenolic compounds. These reports might be used to explain the high total phenolic content (TPC) value of MEMM [31] and supported the UHPLC analysis of MEMM, which demonstrated the presence of various flavonoids-based bioactive compounds (e.g. gallocatechin, epigallocatechin, catechin, chlorogenic acid, caffeic acid, quercetin, quercetin-3-O-glucoside, p-coumatic and hesperidin). In addition to these, the phytochemicals

Table 4 Antinociceptive activity of PEMM assessed by the hot plate test in mice

\begin{tabular}{|c|c|c|c|c|c|c|c|c|}
\hline \multirow[t]{2}{*}{ Treatment } & \multirow{2}{*}{$\begin{array}{l}\text { Dose } \\
(\mathrm{mg} / \\
\mathrm{kg})\end{array}$} & \multicolumn{7}{|c|}{ Latency of discomfort(s) at respective time interval (min) } \\
\hline & & $0 \mathrm{~min}$ & $60 \mathrm{~min}$ & $90 \mathrm{~min}$ & $120 \min$ & $150 \min$ & $180 \mathrm{~min}$ & $210 \mathrm{~min}$ \\
\hline 10\% DMSO & - & $6.97 \pm 0.22$ & $6.97 \pm 022$ & $6.90 \pm 0.23$ & $6.15 \pm 0.15$ & $6.92 \pm 0.23$ & $6.88 \pm 0.29$ & $6.35 \pm 0.17$ \\
\hline Morphine & 5 & $5.77 \pm 0.15$ & $17.37 \pm 1.03^{\mathrm{a}}$ & $18.25 \pm 0.74^{a}$ & $16.52 \pm 1.22^{\mathrm{a}}$ & $13.67 \pm 1.43^{\mathrm{a}}$ & $11.22 \pm 1.11^{\mathrm{a}}$ & $10.48 \pm 0.58^{\mathrm{a}}$ \\
\hline \multirow[t]{3}{*}{ PEMM } & 100 & $6.89 \pm 0.11$ & $9.43 \pm 0.36^{\mathrm{a}}$ & $9.67 \pm 0.22^{\mathrm{a}}$ & $7.68 \pm 0.35$ & $7.36 \pm 0.20$ & $7.51 \pm 0.17$ & $6.95 \pm 0.20$ \\
\hline & 250 & $6.36 \pm 0.27$ & $9.60 \pm 0.24^{\mathrm{ab}}$ & $10.30 \pm 0.30^{\mathrm{ab}}$ & $10.41 \pm 0.60^{\mathrm{ab}}$ & $9.82 \pm 0.44^{\mathrm{ab}}$ & $9.22 \pm 0.20^{a}$ & $7.97 \pm 0.20^{\mathrm{a}}$ \\
\hline & 500 & $6.36 \pm 0.08$ & $11.92 \pm 0.91^{\mathrm{ab}}$ & $13.40 \pm 0.48^{\mathrm{ab}}$ & $13.38 \pm 0.56^{\mathrm{ab}}$ & $12.43 \pm 0.91^{a}$ & $10.33 \pm 0.27^{\mathrm{a}}$ & $9.13 \pm 0.08^{a}$ \\
\hline Naloxone (NLX) & 5 & $6.38 \pm 0.27$ & $6.43 \pm 0.41$ & $5.98 \pm 0.46$ & $6.10 \pm 0.21$ & $5.93 \pm 0.68$ & $6.13 \pm 0.58$ & $5.67 \pm 0.54$ \\
\hline Naloxone + PEMM & $5+500$ & $6.71 \pm 0.20$ & $11.62 \pm 0.72$ & $13.40 \pm 1.00$ & $12.87 \pm 1.00$ & $12.00 \pm 0.56$ & $10.64 \pm 0.27$ & $8.88 \pm 0.29$ \\
\hline
\end{tabular}

${ }^{\text {a }}$ Data differed significantly $(P<0.05)$ when compared against the control (10\% DMSO-treated) group

${ }^{\mathrm{b}}$ Data differed significantly $(P<0.05)$ when compared against the $5 \mathrm{mg} / \mathrm{kg}$ morphine-treated group 


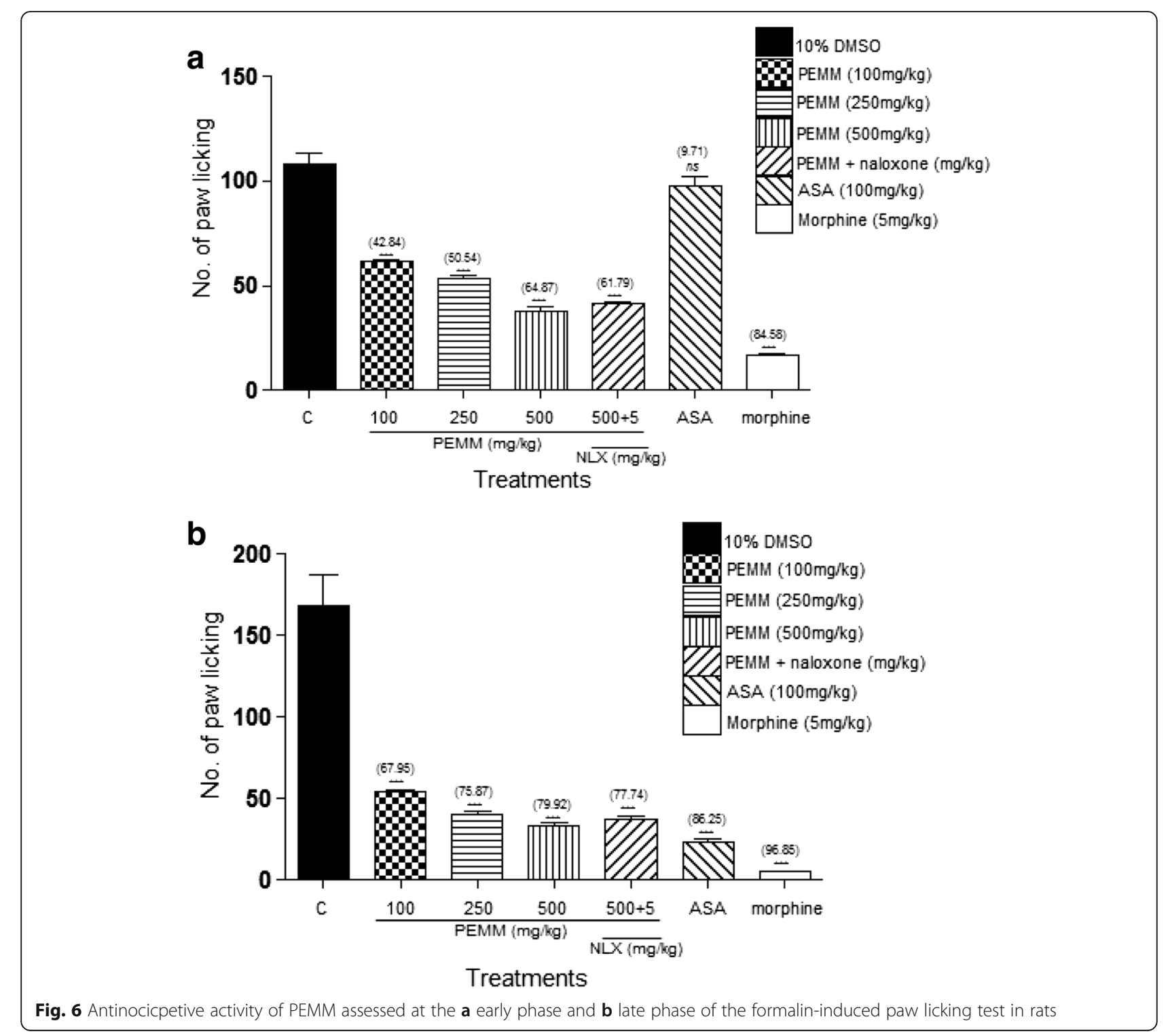

screening of MEMM also demonstrated the high presence of triterpenes, saponins and tannins [31]. Taking into account the presence of various classes of bioactive compounds with different polarity $[27,31]$, further investigations need to be carried out before the bioactive compound(s) responsible for the observed antinociceptive activity could be determined. Thus, the present study was designed to separate the bioactive compounds into non-polar, moderate polar (intermediate) and polar compounds by successive partitioning of MEMM using several solvents with different polarity to obtain the respective PEMM, EAMM and AQMM. It is worthmentioning that this attempt was performed based on suggestion made by Caunii et al. [37] that if the methanol extract expressed remarkable biological activity, further analysis towards isolation and purification of the responsible bioactive compounds should be carried out.

In the present study, the fractions (PEMM, EAMM and AQMM) were first subjected to the antinociceptive study using the abdominal constriction test to assess the antinociceptive efficacy of each extract and the results obtained show that PEMM and EAMM exerted the antinociceptive activity in almost similar intensity. However, PEMM was chosen for further antinociceptive study based on its lower $\mathrm{ED}_{50}$ value in comparison to the EAMM. PEMM was also found to exert antinociceptive activity against the hot plate test and both phases (early and late) of the formalin-induced paw licking test. With regards to the mechanisms of antinociception of PEMM: i) PEMM inhibited the capsaicin- and glutamate-induced paw 


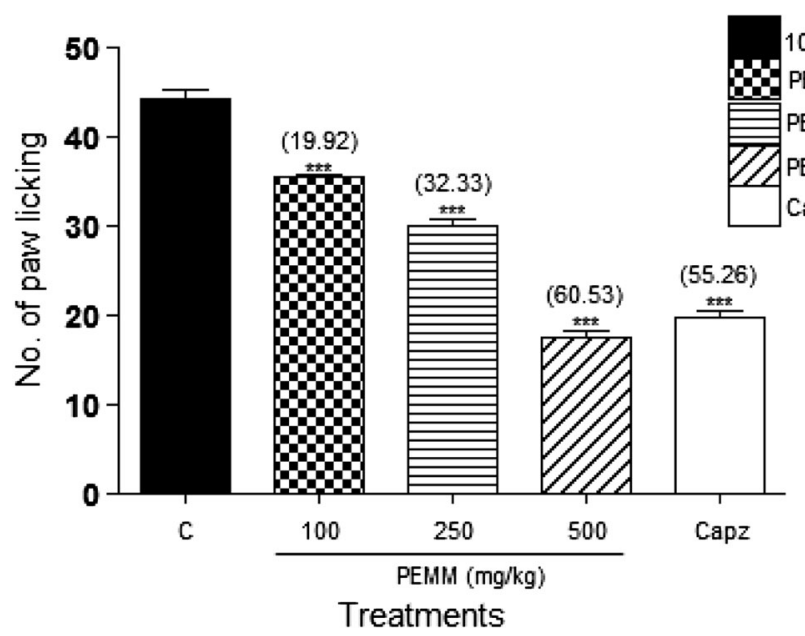

Fig. 7 Antinociceptive activity of PEMM assessed using the capsaicin-induced paw licking test in rats

licking test suggesting the involvement of vanilloid receptors and glutamatergic system, respectively; ii) naloxone (a non-selective opioid antagonist) failed to reverse PEMM antinociceptive activity indicating the non-involvement of opioid receptor system, and; iii) L-arginine (a nitric oxide precursor), but not L-NAME (an inhibitor of NO synthase), MB (an inhibitor of cGMP), or their respective combination, reversed the antinociceptive activity of PEMM suggesting the involvement of NO-mediated/cGMP-independent pathway.

The acetic acid-induced abdominal constriction test has been associated with the activation of peripheral nociceptive processes [38-40] and induction of acute peritoneal inflammation (localized inflammatory response) by the phlogistic agent. Moreover, the latter process occurs via the action of cyclooxygenase (COX) and increase in prostaglandins $\left(\mathrm{PGE}_{2}\right.$ and $\mathrm{PGF}_{2 \alpha}$ ) biosynthesis [35, 40-42].
Hence, any agents capable of inhibiting the action of COX or restricting the synthesis of PGEs could be good antinociceptive agents as seen with the peripherally acting non-steroidal anti-inflamamtory drugs (NSAIDs), ASA $[42,43]$. Interestingly, PEMM also attenuated the aceticacid-induced peripheral nociception indicating the presence of analgesic principles with ability to attenuate inflammatory-mediated pain [44] by acting, partly, to inhibit the action of COX and/or synthesis of PGEs as described earlier. Unfortunately, the abdominal constriction test is considered: i) a non-specific test due to its inability to provide information on the peripheral and/or central nociceptive level inhibited by PEMM [45] and ii) to have poor specificity as it can give false positive results when use to test certain non-analgesic drugs such as muscle relaxants [46]. Thus, the applications of other nociceptive models are necessary before the final

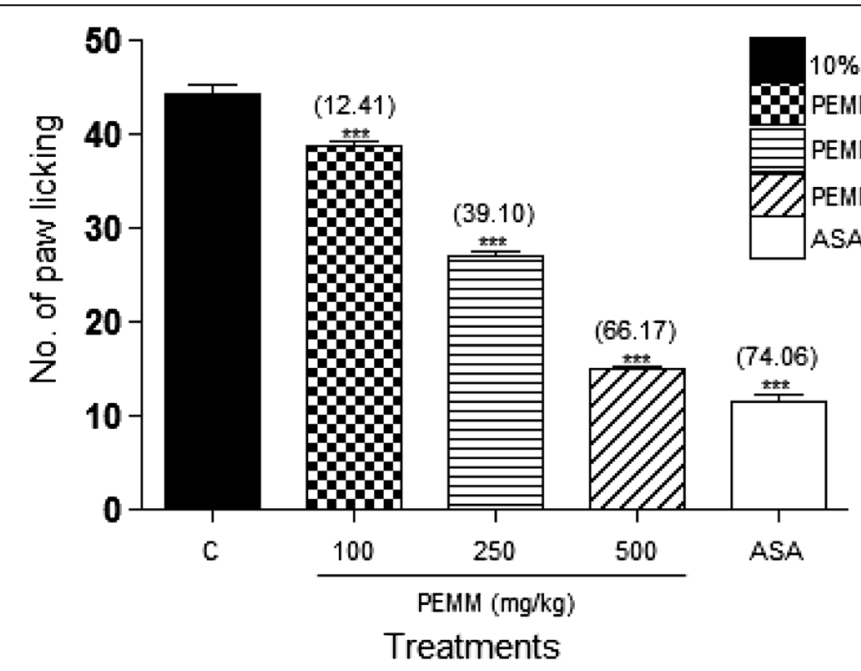

Fig. 8 Antinociceptive activity of PEMM assessed using the glutamate-induced paw licking test in rats 


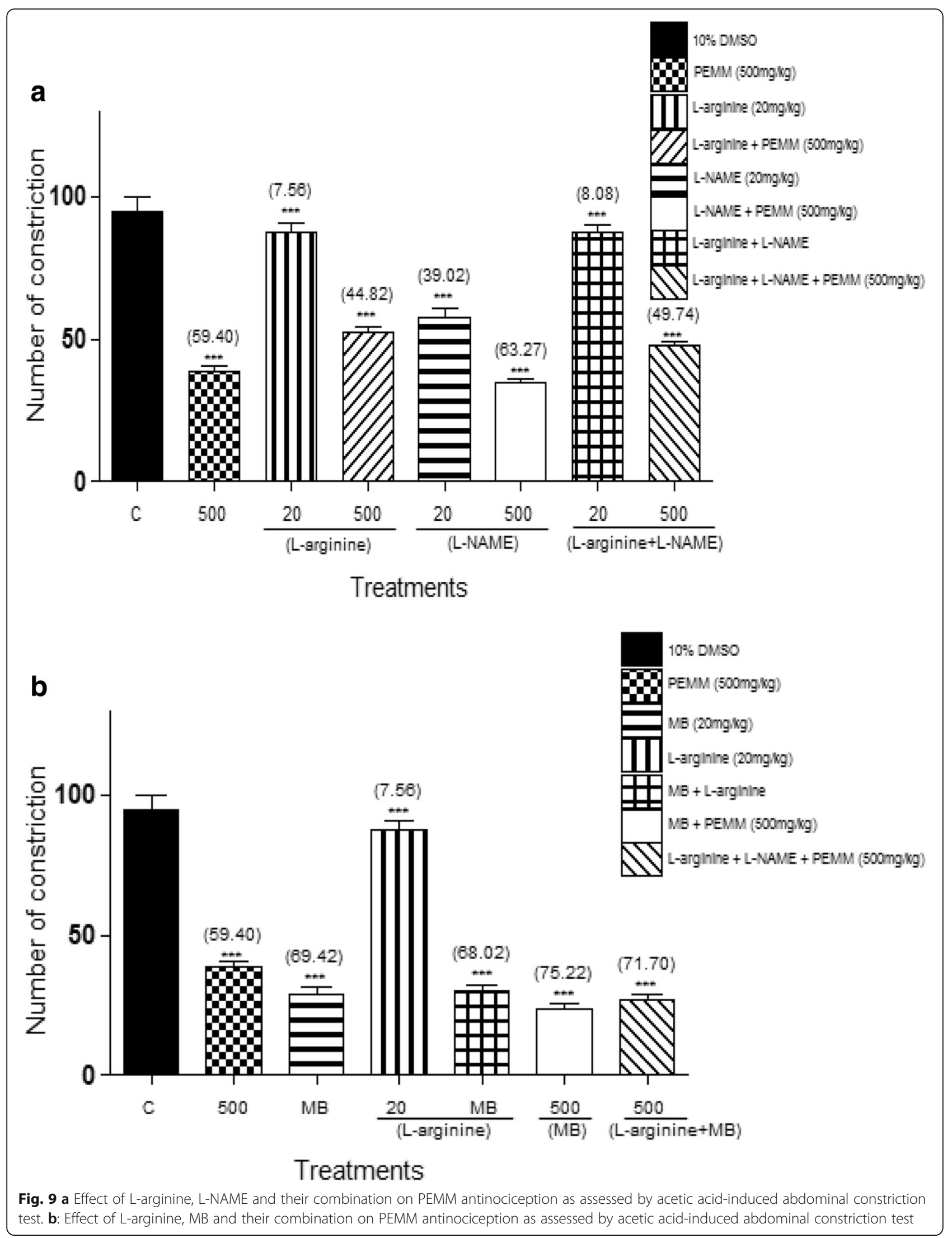


conclusion on the possible mechanisms of action adopted by PEMM could be drawn. In the present study, the hot plate test and formalin-induced paw licking test were adopted to further determine the antinociceptive activity of PEMM.

The hot plate test is selective toward the centrally-acting analgesic drugs such as opioid analgesics (such as morphine) [47] and measures the complex feedback to a non-inflammatory, acute nociceptive input resulting from a brief exposure to a noxious thermal stimulus. In the present study, PEMM successfully attenuated the thermal-induced nociceptive effect suggesting the extract ability to inhibit the central nociceptive center.

Another model of nociception, the formalin-induced paw licking test, is widely used to evaluate the ability of extracts/compounds to affect the peripheral and/or central nociceptive pathways. Being a model of persistent/ continuing pain, the formalin test displays a biphasic response following the administration of formalin known as the early and late phases, which represents the respective centrally- and peripherally-mediated nociception [48]. Drugs acting at the central level (such as morphine) inhibit both phases of the formalin test in comparison to drugs acting at the peripheral level (such as ASA), which inhibit only the late phase. In the present study, PEMM was also found to inhibit both phases of the formalininduced nociception, thus, further suggesting its ability to block the central nociceptive center. Overall, findings obtained from the three nociceptive assays implied that PEMM contains non-polar bioactive compound(s) with ability to modulate the central and peripheral nociceptive mechanisms. PEMM was also able to attenuate both the non-inflammatory- and inflammatory-mediated pain.

The roles of opioid receptors in the regulation of modulation of nociceptive processing have been demonstrated in many previous studies $[49,50]$. However, the effectiveness of opioid analgesics (such as morphine) has been overshadowed by many adverse side effects (e.g. respiratory depression, vomiting, nausea, constipation, tolerance, and dependence). This is further worsening by the fact that prolongs use of morphine leads to the development of analgesic tolerance, which requires dosage increases to maintain its analgesic effect. This is problematic since dosage increases also amplify the frequency and severity of its side effects. Therefore, searching or developing new analgesics without these side effects is imperative. The non-opioid activity exerted by PEMM despite its ability to act centrally and peripherally as seen with morphine seems to be an added advantage when discussed in contact of finding new and alternative analgesics with unwanted side effects.

Furthermore, the roles of vanilloid receptors, also known as transient receptor potential cation channel subfamily $\mathrm{V}$ member 1 (TRPV1), and glutamatergic system in the regulation of nociceptive transmission have been reported elsewhere [51, 52]. Vanilloid receptors, are activated by capsaicin, an active ingredient in hot chili peppers, and selectively acting on neurones within the peripheral and central nervous systems [53, 54]. The present study shows that PEMM possessed antagonistic effect against the vanilloid receptors based on its ability to inhibit nociceptive transmission modulated via the vanilloid receptors. This observation was supported by earlier researches that reported on the ability of antagonists of TRPV1 receptors to exert antinociceptive activity and, to attenuate inflammatory- and neuropathic-pain $[51,52]$.

On the other hand, the glutamatergic system (glutamate and glutamatergic receptors) has also been acknowledged to be vital in the peripheral, spinal, and supraspinal nociceptive neurotransmission [55]. Activation of glutamatergic receptors, to a great extent, is interceded by both N-methyl-D-aspartate (NMDA) and non-NMDA receptors, and the presence or absence of $\mathrm{NO}$ and $\mathrm{NO}$ related substances [56]. Furthermore, earlier report by Dickenson and Sullivan [57] shows that the antagonists of NMDA receptor block the spread of pain sensation and lessen the hyperexcitability of spinal cord neurons generated by $\mathrm{C}$-fiber stimulation. In line with the abovementioned reports, the present study revealed the ability of PEMM to attenuate the glutamate-induced nociceptive effect, which could possibly be achieved by acting as an NMDA receptor antagonist or by modulating the $\mathrm{NO}$-mediated pathway. Interestingly, the next findings did support the latter claim that PEMM attenuated glutamate-induced nociception via the NO-mediated pathway.

The role of NO/cGMP pathway in the modulation of nociceptive transmission at the PNS and CNS levels has been well documented $[58,59]$. In the earlier discussion we have highlighted that PEMM exerts a characteristic of morphine by acting at the central and peripheral nociceptive levels. Since morphine also exhibits antinociceptive activity via the NO/cGMP pathway activation $[60,61]$, there is a need to also evaluate the involvement of NO/cGMP pathway in the antinociceptive activity of PEMM. In the present study, PEMM antinociception was reversed by high level of NO (due to presence of L-arginine alone) but was not affected by low level of NO (due to the presence of L-NAME alone). This observation is concurrent with suggestion that the effect of $\mathrm{NO}$ on nociceptive response depends on dosage levels and the rate and timing of its release $[58,59]$. As mentioned earlier, the presence of $\mathrm{NO}$ activates soluble guanylyl cyclase (sGC) leading to increase in cGMP levels, which in turn affects pain and analgesia. The role of cGMP pathway in the modulation of nociceptive process was observed when $\mathrm{MB}$, an inhibitor of cGMP pathway, exerted antinociceptive activity when 
given alone. However, MB failed to affect the antinociceptive activity of PEMM suggesting that the antinociceptive activity of PEMM did not involved modulation of cGMP pathway. This finding also indicates that PEMM might trigger antinociceptive activity via the NO-dependent/cGMP-independent pathway. Moreover, since opioids like morphine induced antinociceptive activity via the NO/cGMP pathway, it seems reasonable to suggest that the non-opioid-acting PEMM triggered antinociceptive activity via a different pathway mediated by NO, but independent of cGMP activity (NO-mediated/ cGMP-independent pathway). The role of NO-dependent/ cGMP-independent pathway in the modulation of antinociceptive activity has been reported by Morioka et al. [62] and could be used to support the present observations.

Previous phytochemical screening of MEMM demonstrated the strong presence of flavonoids, triterpenes, tannins, saponins and steroids, but no alkaloids in the leaves of M. malabathricum [31]. On the other hand, the phytochemical screening of PEMM demonstrated the strong presence of only triterpenes with low presence of flavonoids, tannins and saponins. The low presence of flavonoids in PEMM particularly was further supported by the HPLC and UHPLC-ESI analyses. In the former analysis, only two peaks were detected at $366 \mathrm{~nm}$, which upon comparison of retention time and chromatogram against 10 pure flavonoids did not match to any of them, thus, suggesting their absence in PEMM. In the latter analysis, only two small peaks were detected and identified as gallocatechin and epigallocatechin, respectively. In support of the phytochemical screenining of PEMM, Nurestri et. al. [63] isolated three pentacyclic triterpenoids, namely ursolic acid, 2-hydroxyursolic acid and asiatic acid in addition to glycerol-1,2-dilinolenyl-3-O- $\beta$-D-galactopyranoside and glycerol 1,2-dilinolenyl- 3-O-(4,6-di-O-isopropylidene)- $\beta$ D-galactopyranoside from MEMM while partitioning of MEMM using hexane (HEMM), which is also grouped as a non-polar solvent like petroleum ether, lead to the isolation of a triterpene ( $\alpha$-amyrin) and two amides (patriscabatrine and auranamide) [25]. Based on the presence of triterpene-based compounds as described above, further explanation with regards to the possible mechanisms of antinociception of PEMM could be plausibly suggested. For examples; i) $3 \beta, 6 \beta, 16 \beta$-trihydroxylup20(29)-ene inhibited glutamate- and formalin-induced nociceptive models, and exert antinociceptive activity that is dependent on the opioid and serotonergic systems [64]; ii) siaresinolic acid reduced the acetic acid-induced nociceptive response via the activation of non-opioid system and ATP-dependent potassium channels [65]; iii) 24-hydroxytormentic acid inhibited the acetic acidand formalin-, but not thermal-induced nociception via mechanism that did not involve modulation of the opioid, nitric oxide or serotonin systems [66], and; iv) $\alpha$-amyrin and $\beta$-amyrin, in mixture, exerted significant antinociception only against the acetic acid-, capsaicin-, glutamateand formalin-, but not thermal-induced nociceptive models in mice. Interestingly, this mixture also exhibited a nonopioid-mediated antinociceptive activity [67]. As described above, two reports $[66,67]$ on the failure of triterpenes to attenuate thermal-induced nocicpetion seems to contradict our findings with triterpene-rich PEMM. This discrepancy could be attributed to the low dose $(30 \mathrm{mg} / \mathrm{kg})$ of pure triterpenes used by those authors whereas in the present study PEMM fraction was effective only at the doses of 250 and $500 \mathrm{mg} / \mathrm{kg}$.

Further analysis using the GCMS method on the presence of volatile compounds in PEMM revealed the presence of 29 volatile compounds of which five are the major compounds, namely, oleoamide (9-octadecenamide) (11.54\%), 23-ethyl- (3ß-23S)-cholest-5-en-3-ol (10.06\%), palmitic acid (6.95\%), phthalic acid (5.90\%) and linolenic acid methyl ester (5.69\%). Of these, at least, oleoamide and palmitic acid has been reported to show some pharmacological activities related to the antinociceptive activity of PEMM. Oleamide, for example, has been reported to exert anti-inflammatory activity when assessed using the lipopolysaccharide (LPS)-induced BV2 microglial [68]. The inhibition of inflammation occurs via inhibition of $\mathrm{NO}$ and $\mathrm{PGE}_{2}$ production. Moreover, oleamide also inhibits the activation of NFKB and PI 3-kinase, as well as the phosphorylation of inhibitor $\kappa B$ kinase, Akt, p38 MAPK, and ERK, and accumulation of reactive oxygen species (ROS) induced by LPS on BV2 microglial. On the other hand, Déciga-Campos et al. [69] have earlier reported on the antinociceptive activity of several palmitic acid derivatives, namely N-(4-Methoxy-2nitrophenyl)hexadecanamide, 2-amino-3-(palmitoylamino) benzoic acid or 4-amino-3-(palmi-toylamino)benzoic acid when assessed using the abdominal constriction and hot plate tests.

\section{Conclusion}

In conclusion, PEMM is suggested to demonstrate the non-opioid mediated antinociceptive activity at the peripheral and central level partly via the modulation of the vanilloid receptors, glutamatergic system and NO-mediated/ cGMP-independent pathway. On the other hand, the antinociceptive potential of PEMM might be attributed, in part, to the presence of oleoamide and palmitic acid, the volatile compounds with pain relieving activity, as well as the higher content of triterpenes. Flavonoids, proven to be presence in low quantity in PEMM via the phytochemical screening and HPLC analyses, was further supported by the HPLC-ESI analysis that further shows the presence of low content of gallocatechin and epigallocatechin, might work synergistically with tannins and/or saponins, which also presence in low content, to further enhance the 
antinociceptive action of oleoamide and palmitic acid, and triterpenes.

\begin{abstract}
Abbreviations
ANOVA: One-way analysis of variance; AQMM: Aqueous partition of $M$. malabathricum; ASA: Acetylsalicylic acid; CGMP: Cyclic guanosine monophosphate; COX: Cyclo-oxygenase; DMSO: Dimethyl sulfoxide; EAMM: Ethyl acetate partition of M. malabathricum; $\mathrm{EC}_{50}$ : Effective concentration that inhibits $50 \%$ of the population of sample; GCMS: Gas chromatography/mass spectrophotometry; HPLC-ESI: High performance liquid chromatography-electrospray ionization; IACUC: International Animal Care and Use Committee; L-NAME: $N^{G}$-nitro-L-arginine methyl esters; $M$. malabathricum: Melastoma malabathricum; MB: Methylene blue; MEMM: Methanol extract of M. malabathricum; NLX: Naloxone; NO: Nitric oxide; NO/cGMP: Nitric oxide/cyclic guanosine phosphate; PEMM: Petroleum ether partition of $M$. malabathricum: TPC: Total phenolic content: TRPV1: Transient receptor potential cation channel subfamily $\vee$ member 1 ; UPM: Universiti Putra Malaysia
\end{abstract}

\section{Acknowledgements}

The authors thanked the Faculty of Medicine and Health Sciences, Universiti Putra Malaysia, Malaysia for providing the facilities to carry out this research.

\section{Funding}

This research was supported by the Putra Research Grant Scheme (Postgraduate Initiative; Reference no: GP-IPS/2015/9462500) and the Research Acculturation Collaborative Effort (RACE; Reference no. R/RACE/A07.00/00290A/002/2015/ 000234) awarded by the UPM, Malaysia.

\section{Availability of data and materials}

The supporting materials can be obtained upon request via email to the corresponding author.

\section{Authors' contributions}

ESJ, is a postgraduates students, who collectively performed all experiments and data analyses, and prepared the draft of the manuscript. MHO, SD and MT helped in the phytochemicals analyses using the UHPLC-ESI, HPLC and GCMS methods. SAR and SMC involved in the statistical analysis of the data obtained and also helped to improve the draft of manuscript. SSAH provided the reagents/analysis tools and helped to improve the manuscript. ZAZ, with the helped by LKT and MZS, designed the experiment, provided the reagents/analysis tools and corrected the draft of manuscript. All authors read and approved the final manuscript.

\section{Competing interests}

The authors declare that they have no competing interests.

\section{Consent for publication}

Not applicable.

\section{Ethics approval}

The study protocol involving the use of animals in the present study was approved by the Animal Ethics Committee of Integrated Centre for Research of Animal Care and Use (ICRACU), Faculty of Allied Sciences, International Islamic University Malaysia [Ethical approval no.: IIUM/IACUC Approval/2016/ (9) (58)].

\section{Author details}

${ }^{1}$ Department of Biomedical Sciences, Faculty of Medicine and Health Sciences, Universiti Putra Malaysia (UPM), 43400 Serdang, Selangor D.E, Malaysia. ${ }^{2}$ Integrative Pharmacogenomics Institute (iPROMISE), Universiti Teknologi MARA (UiTM), Level 7, FF3 Building, 42300 Puncak Alam, Selangor D.E, Malaysia. ${ }^{3}$ Phytochemistry Unit, Herbal Medicine Research Centre, Institute for Medical Research, JalanPahang 50588 Kuala Lumpur, Malaysia. ${ }^{4}$ Department of Biomedical Sciences, Kulliyyah of Allied Health Sciences, International Islamic University Malaysia (IIUM), 25200 Kuantan, Pahang D.M, Malaysia. ${ }^{5}$ Medical Technology Division, Malaysian Nuclear Agency, 43000 Bangi, Kajang, Selangor, Malaysia. ${ }^{6}$ Department of Family Medicine, Faculty of Medicine and Health Sciences, Universiti Putra Malaysia (UPM), 43400 Serdang, Selangor D.E, Malaysia. 'Department of Chemistry, Kulliyyah of Sciences, International Islamic University Malaysia (IIUM), 25200 Kuantan,
Pahang D.M, Malaysia. ${ }^{8}$ Department of Pharmaceutical Technology, Kulliyyah of Pharmacy, International Islamic University Malaysia (IIUM), 25200 Kuantan, Pahang D.M, Malaysia.

Received: 4 June 2016 Accepted: 7 November 2016

Published online: 29 November 2016

\section{References}

1. Raghav SK, Gupta B, Agrawal C, Goswami K, Das HR. Anti-inflammatory effect of ruta graveolens (L). inmurine macrophage cells. J Ethnopharmacol. 2006;104:234-9.

2. Rang HP, Dale MM, Ritter JM, Flower RJ, Henderson G. Pharmacology. 7th ed. Edinburg: Els Chur Livingstone; 2011.

3. Rustoen T, Stubhaug A, Eidsmo I, Westheim A, Paul SM, Miaskowski C. Pain and quality of life in hospitalized patients with heart failure. J Pain Symptom Manag. 2008;36:497-504.

4. Gureje O, Von Korff M, Simon GE, Gater R. Persistent pain and well-being: a world health organization study in primary care. JAMA. 1998;280:147-51.

5. Williams M, Kowaluk EA, Arneric SP. Emerging molecular approaches to pain therapy. J Med Chem. 1999;42:1481-500.

6. Levine JD. New directions in pain research: molecules to maladies. Neuron. 1998;20:649-54.

7. McQuay H, Moore A, Justins D. Fortnightly review: treating acute pain in hospital. BMJ. 1997;314:1531.

8. Walsh TD. Prevention of opioid side effects. J Pain Symptom Manag. 1990;5:362-7.

9. Allison MC, Howatson AG, Torrance CJ, Lee FD, Russell RI. Gastrointestinal damage associated with the use of nonsteroidal anti-inflammatory drugs. $\mathrm{N}$ Engl J Med. 1992;327:749-54.

10. South African Medicines Formulary (SAMF). Health and Medical Publishing Group of the South African Medical Association, Cape Town, South Africa, 9th Ed 2010.

11. Martini-Bettolo GB. Present aspects of the use of plants in traditional medicine. J Ethnopharmacol. 1980;2:5-7.

12. Akinmoladun AC, Ibukun EO, Afor E, Obuotor EM, Farombi EO. Phytochemical constituent and antioxidant activity of extract from the leaves of Ocimum gratissimum. Sci Res Essay. 2007;2:163-6.

13. Verpoorte R. Exploration of nature's chemodiversity: the role of secondary metabolites as leads in drug development. Drug Discov Today. 1998:3:232-8.

14. Rajenderan MT. Ethno medicinal uses and antimicrobial properties of Melastoma malabathricum. SEGi Rev. 2010;3:34-44.

15. Ong HC, Nordiana M. Malay ethno-medico botany in Machang, Kelantan, Malaysia. Fitoterapia. 1999;70:502-13.

16. Sulaiman MR, Somchit MN, Israf DA, Ahmad Z, Moin S. Antinociceptive effect of Melastoma malabathricum $(\mathrm{L})$ ethanolic extract in mice. Fitoterapia. 2004;75:667-72.

17. Roosita K, Kusharto CM, Sekiyama M, Fachrurozi M, Ohtsuka R. Medicinal plants used by the villagers of a Sundanese community in West Java, Indonesia. J Ethnopharmacol. 2008;115:72-81.

18. Grosvenor PW, Gothard PK, MC William NC, Supriono A, Gray DO. Medicinal plants from Riau Province, Sumatra, Indonesia. Part 1: uses. J Ethnopharmacol. 1995;45:75-95.

19. Sharma HK, Chhangte L, Dolui AK. Traditional medicinal plants in Mizoram, India. Fitoterapia. 2001;72:146-61.

20. Sunilson JAJ, Anandarajagopal K, Kumari AVAG, Mohan S. Antidiarrhoeal activity of leaves of Melastoma malabathricum (L). Indian J Pharmaceutic Sci. 2009;71:691-5.

21. Wiart C, Mogana S, Khalifah S, Mahan M, Ismail S, Buckle M, Narayana AK, Sulaiman M. Antimicrobial screening of plants used for traditional medicine in the state of Perak, Peninsular Malaysia. Fitoterapia. 2004;75:68-73.

22. Nazlina I, Norha S, Noor Zarina AW, Ahmad IB. Cytotoxicity and antiviral activity of Melastoma malabathricum (L) extracts. Malays J Appl Biol. 2008;37:53-5.

23. Susanti D, Sirat HM, Ahmad F, Mat Ali R. Bioactive constituents from the leaves of Melastoma malabathricum (L). Jurnal IImiah Farmasi. 2008;5:1-8.

24. Zakaria ZA, Raden MNRNS, Hanan Kumar G. Antinociceptive, anti-inflammatory and antipyretic properties of Melastoma malabathricum $(\mathrm{L})$ leaves aqueous extract in experimental animals. Can J Physiol Pharm. 2008;84:1291-9.

25. Manicam C, Abdullah JO, Mohd Tohit ER, Seman Z, Sieo CC, Hamid M. In vitro anticoagulant activities of Melastoma malabathricum $(\mathrm{L})$ aqueous leaf extract: a preliminary novel finding. J Med Plants Res. 2010;4:1464-72. 
26. Hussain F, Abdulla MA, Noor SM, Ismail S, Ali HM. Gastroprotective effects of Melastoma malabathricum $(\mathrm{L})$ aqueous leaf extract against ethanol-induced gastric ulcer in rats. Am J Biochem Biotechnol. 2008:4:438-41.

27. Jaios ES, Abdul Rahman S, Ching SM, Arifah AK, Desa MN, Zakaria ZA. Possible mechanisms of antinociception of methanol extract of Melastoma malabathricum leaves. Rev Bras Farmacogn. 2016;26:584-94.

28. Sowndhararajan K, Kang SC. Protective effect of ethyl acetate fraction of Acacia ferruginea DC against ethanol-induced gastric ulcer in rats. J Ethnopharmacol. 2013;148:175-81.

29. Ikhiri K, Boureima D, Dan-Kouloudo D. Chemical screening of medicinal plants used in the traditional pharmacopoeia of Niger. Int J Pharmacog. 1992;30:251-62.

30. Kamisan FH, Yahya FA, Mamat SS, Kamarolzaman MFF, Suhaili Z, Mohtarrudin $\mathrm{N}$, et al. Effect of methanol extract of dicranopteris linearis against carbon tetrachloride-induced acute liver injury in rats. BMC Compliment Alt Med. 2014;14:123.

31. Mamat SS, Kamarolzaman MFF, Yahya F, Mahmood ND, Shahril MS, Jakius KF, Mohtarrudin N, Ching SM, Deny S, Taher M, Zakaria ZA. Methanol extract of Melastoma malabathricum $(\mathrm{L})$ leaves exerted antioxidant and liver protective activity in rats. BMC Complement Altern Med. 2013;13:326.

32. Zakaria ZA, Balan T, Azemi AK, Omar MH, Mohtarrudin N, Zuraini A, Abdullah MNH, Teh LK, Salleh MZ. Mechanism(s) of action underlying the gastroprotective effect of ethyl acetate fraction obtained from the crude methanolic leaves extract of Muntingia calabura. BMC Complement Alt Med. 2016;16:78.

33. Zimmermann M. Ethical guidelines for investigations of experimental pain in conscious animals. Pain. 1983;16:109-10.

34. OECD. Test No. 423: acute oral toxicity - acute toxic class method. OECD guidelines for the testing of chemicals (section 4: health effects). 2001. p. 1-14.

35. Mohd Sani MH, Zakaria ZA, Balan T, Teh LK, Salleh MZ. Antinociceptive activity of methanol extract of Muntingia calabura leaves and the mechanisms of action involved. Evid Based Complement Alternat Med. 2012;2012:890361.

36. Ahmad A, Alkarkhi AA, Hena S, Lim HK. Extraction, separation and identification of chemical ingredients of Elephantopus scaber $(\mathrm{L})$ using factorial design of experiment. Int J Chem. 2009;1:36-49.

37. Angela C, George P, loana G, Dorin G, lonel S. Design of optimal solvent for extraction of bio-active ingredients from six varieties of Medicago sativa. J Chem Ctrl. 2012;6:123. doi:10.1186/1752-153X-6-123.

38. Vyklicky L. Techniques for the study of pain in animals. In: Bonica JJ, Liebeskind JC, Albe-Fessard DG, editors. Advances in pain research and therapy. New York: Raven; 1979.

39. Smith TW, Buchan P, Parsons DN, Wilkinson S. Peripheral antinociceptive effects of N-methyl morphine. Life Sci. 1982;31:1205-8.

40. Arif Ullah HM, Zaman S, Juhara F, Akter L, Tareq SM, Masum EH, Bhattacharjee R. Evaluation of antinociceptive, in-vivo \& in-vitro antiinflammatory activity of ethanolic extract of Curcuma zedoaria rhizome. BMC Complement Altern Med. 2014;14:346. doi:10.1186/1472-6882-14-346.

41. Duarte I, Lorenzetti B, Ferreira S. Peripheral analgesia and activation of the nitric oxide-cyclic GMP pathway. Eur J Pharmacol. 1990;186:289-93.

42. Deraedt R, Jouquey S, Delevallee F, Flahaut M. Release of prostaglandins E and $F$ in an algogenic reaction and its inhibition. Eur J Pharmacol. 1980;61:17-24.

43. Marchioro M, Blank MFA, Mourão RHV, Antoniolli AR. Antinociceptive activity of the aqueous extract of Erythrina velutina leaves. Fitoterapia. 2005;76:637-42

44. Park S-H, Sim Y-B, Lim S-S, Kim J-K, Lee J-K, Suh H-W. Antinociception effect and mechanisms of Campanula punctata extract in the mouse. Korean Physiol Pharmacol. 2010;14:285-9

45. Chen YF, Tsai HY, Wu TS. Anti-inflammatory and analgesic activities from roots of Angelica pubescens. Planta Med. 1995;1:2-8.

46. Le Bars D, Gozariu M, Cadden SW. Animal models of nociception. Pharm Rev. 2001:4:597-652

47. Giglio CA, Defino HLA, Da Silva CA, De Souza AS, Del Bel EA. Behavioral and physiological methods for early quantitative assessment of spinal cord injury and prognosis in rats. Braz J Medic Bio Res. 2006;12:1613-23.

48. Vaz ZR, Cechinel V, Yunes RA, Calixto JB. Antinociceptive action of 2-(4bromobenzoyl)-3-methyl-4-6-dimethoxy bezofuran, a novel xanthoxyline derivative of chemical and thermal models of nociception in mice. J Pharm Exp Ther. 1996;278:304-12.

49. Clark SJ, Follenfant RL, Smith TW. Evaluation of opioid-induced antinociceptive effects in anaesthetized and conscious animals. Br J Pharmacol. 1988;1:275-83.

50. Ossipov MH, Lai J, King T, Vanderah TW, Malan Jr TP, Hruby VJ, Porreca F. Antinociceptive and nociceptive actions of opioids. J Neurobiol. 2004;1:126-48.
51. Jhaveri MD, Elmes SJR, Kendall DA, Chapman V. Inhibition of peripheral vanilloid TRPV1 receptors reduces noxious heat-evoked responses of dorsal horn neurons in naïve, carrageenan-inflamed and neuropathic rats. Eur J Neuro. 2005:2:361-70.

52. Khairatkar-Joshi N, Szallasi A. TRPV1 antagonists: the challenges for therapeutic targeting. Trends in Mol Med. 2009;1:14-22.

53. Szolcsányi J. Actions of capsaicin on sensory receptors. In: Wood J, editor. Capsaicin in the study of pain. London: Academic; 1993. p. 1-26.

54. Cui M, Honore P, Zhong C, Gauvin D, Mikusa J, Hernandez G, Faltynek CR. TRPV1 receptors in the CNS play a key role in broad-spectrum analgesia of TRPV1 antagonists. J Neuro. 2006:37:9385-93.

55. Fundytus ME. Glutamate receptors and nociception: implications for the drug treatment of pain. CNS Drug. 2001;1:29-58

56. Beirith A, Santos AR, Calixto JB. Mechanism underlying the nociception and paw edema caused by injection of glutamate into the mouse paw. Brain Res. 2002;924:219-28.

57. Dickenson AH, Sullivan AF. Evidence for a role of the NMDA receptor in the frequency dependent potentiation of deep rat dorsal horn nociceptive neurones following C fibre stimulation. Neuropharmacol. 1987;26:1235-8.

58. Meller ST, Gebhart GF. Nitric oxide (NO) and nociceptive processing in the spinal cord. Pain. 1993;52:127-36.

59. Talarek S, Fidecka S. Role of nitric oxide in benzodiazepines-induced antinociception in mice. Polish J Pharmacol. 2002;54:27-34.

60. Granados-Soto V, Rufino MDO, Gomes Lopes LD, Ferreira SH. Evidence for the involvement of the nitric oxide-cGMP pathway in the antinociception ofmorphine in the formalin tests. Eur J Pharmacol. 1997;2-3:177-80.

61. Cury Y, Picolo G, Gutierrez VP, Ferreira SH. Pain and analgesia: the dual effect of nitric oxide in the nociceptive system. Nitric Oxide. 2011:3:243-54.

62. Morioka N, Inoue A, Hanada T, Kumagai K, Takeda K, Ikoma K, Hide I, Tamura Y, Shiomi H, Dohi T, Nakata Y. Nitric oxide synergistically potentiates interleukin-1 $\beta$-induced increase of cyclooxygenase-2 mRNA levels, resulting in the facilitation of substance $P$ release fromprimary afferent neurons: involvement of CGMP-independent mechanisms. Neuropharmacol. 2002;5:868-76.

63. Nuresti S, Baek SH, Asari A. Chemical components of Melastoma malabathricum. ACGC Chem Res Comm. 2003;16:28-33.

64. Longhi-Balbinot DT, Martins DF, Lanznaster D, Silva MD, Facundo VA, Santos AR. Further analyses of mechanisms underlying the antinociceptive effect of the triterpene 3 $3,6 \beta, 16 \beta$-trihydroxylup-20(29)-ene in mice. Eur J Pharmacol. $2011 ; 653: 32-40$

65. de Oliveira AM de Araújo AF, Lyra Lemos RP, Conserva LM, de Souza Ferro JN, Barreto E. Antinociceptive and anti-inflammatory activity of the siaresinolic acid, a triterpene isolated from the leaves of Sabicea grisea Cham. \& Schltdl. var. grisea. J Nat Med. 2015:69:232-40.

66. Beirith A, Santos AR, Calixto JB, Hess SC, Messana I, Ferrari F, Yunes RA. Study of the antinociceptive action of the ethanolic extract and the triterpene 24-hydroxytormentic acid isolated from the stem bark of Ocotea suaveolens. Planta Med. 1999:65:50-5.

67. Otuki MF, Ferreira J, Lima FV, Meyre-Silva C, Malheiros A, Muller LA, Cani GS, Santos ARS, Yunes RA, Calixto JB. Antinociceptive properties of mixture of a-amyrin and $\beta$-amyrin triterpenes: evidence for participation of protein kinase $C$ and protein kinase a pathways. J Pharmacol Exp Ther. 2005;313:310-8.

68. Oh YT, Lee JY, Lee J, Lee JH, Kim JE, Ha J, Kang I. Oleamide suppresses lipopolysaccharideinduced expression of iNOS and COX-2 through inhibition of NF-kappaB activation in BV2 murine microglial cells. Neurosci Lett. 2010;474:148-153.

69. Déciga-Campos M, Montiel-Ruiz RM, Navarrete-Vázquez G, López-Muñoz FJ. Palmitic acid analogues exhibiting antinociceptive activity in mice. Proc West Pharmacol Soc. 2007:50:75-7. 